\title{
Article \\ A Comparative Transcriptomic Meta-Analysis Revealed Conserved Key Genes and Regulatory Networks Involved in Drought Tolerance in Cereal Crops
}

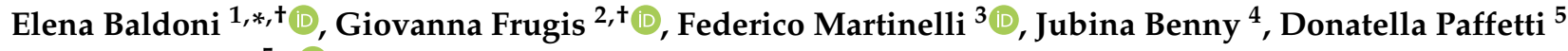 \\ and Matteo Buti $5, * \mathbb{D}$ \\ 1 National Research Council (CNR), Institute of Agricultural Biology and Biotechnology (IBBA), \\ Via Alfonso Corti 12, 20133 Milan, Italy \\ 2 National Research Council (CNR), Institute of Agricultural Biology and Biotechnology (IBBA), Rome Unit, \\ Via Salaria Km. 29,300, 00015 Monterotondo, Italy; giovanna.frugis@cnr.it \\ 3 Department of Biology, University of Florence, 50019 Sesto Fiorentino, Italy; federico.martinelli@unifi.it \\ 4 Department of Agricultural, Food and Forest Sciences, University of Palermo, 90133 Palermo, Italy; \\ jubina.benny@unipa.it \\ 5 Department of Agriculture, Food, Environment and Forestry (DAGRI), University of Florence, \\ 50144 Florence, Italy; donatella.paffetti@unifi.it \\ * Correspondence: elena.baldoni@cnr.it (E.B.); matteo.buti@unifi.it (M.B.) \\ + These authors contributed equally to this work.
}

check for updates

Citation: Baldoni, E.; Frugis, G.; Martinelli, F.; Benny, J.; Paffetti, D.; Buti, M. A Comparative

Transcriptomic Meta-Analysis Revealed Conserved Key Genes and Regulatory Networks Involved in Drought Tolerance in Cereal Crops. Int. J. Mol. Sci. 2021, 22, 13062. https://doi.org/10.3390/ijms222313062

Academic Editor: Prasanta

K. Subudhi

Received: 30 September 2021

Accepted: 30 November 2021

Published: 2 December 2021

Publisher's Note: MDPI stays neutral with regard to jurisdictional claims in published maps and institutional affiliations.

Copyright: (c) 2021 by the authors. Licensee MDPI, Basel, Switzerland. This article is an open access article distributed under the terms and conditions of the Creative Commons Attribution (CC BY) license (https:// creativecommons.org/licenses/by/ $4.0 /)$

\begin{abstract}
Drought affects plant growth and development, causing severe yield losses, especially in cereal crops. The identification of genes involved in drought tolerance is crucial for the development of drought-tolerant crops. The aim of this study was to identify genes that are conserved key players for conferring drought tolerance in cereals. By comparing the transcriptomic changes between tolerant and susceptible genotypes in four Gramineae species, we identified 69 conserved drought tolerantrelated (CDT) genes that are potentially involved in the drought tolerance of all of the analysed species. The CDT genes are principally involved in stress response, photosynthesis, chlorophyll biogenesis, secondary metabolism, jasmonic acid signalling, and cellular transport. Twenty CDT genes are not yet characterized and can be novel candidates for drought tolerance. The k-means clustering analysis of expression data highlighted the prominent roles of photosynthesis and leaf senescence-related mechanisms in differentiating the drought response between tolerant and sensitive genotypes. In addition, we identified specific transcription factors that could regulate the expression of photosynthesis and leaf senescence-related genes. Our analysis suggests that the balance between the induction of leaf senescence and maintenance of photosynthesis during drought plays a major role in tolerance. Fine-tuning of CDT gene expression modulation by specific transcription factors can be the key to improving drought tolerance in cereals.
\end{abstract}

Keywords: rice; barley; Brachypodium; maize; drought tolerance; comparative transcriptomics; stay-green rice; photosynthesis; transcription factors

\section{Introduction}

Cereal crops are a major source of food for humans and livestock throughout the world (FAO statistics, http:/ / www.fao.org/faostat/en/\#data, accessed on 30 September 2021). Due to the increasing world population, enhancing food security is an urgent need; however, the production of cereals is endangered by global warming and related abiotic stressors, such as heat, drought, and salinity [1,2]. Drought is one of the most critical global warmingrelated stress factors affecting crop growth and development, and leads to severe yield loss $[3,4]$. Water deficiency is a global concern since even the most productive agricultural regions can occasionally experience short periods or years of severe drought. Furthermore, irrigation use might be restricted in the future due to the competition from non-agricultural 
activities, such as industry and urbanisation [5]. In the future, the potential impact of climate change on rainfall patterns and the need to extend the exploitation of marginal lands will further reduce the availability of water for agriculture. Therefore, a large effort is required to increase agricultural production by improving the adaptation of crops to sub-optimal environments in spite of reduced water availability $[4,5]$.

Plants have evolved several morphological, physiological, biochemical, and molecular mechanisms to overcome drought stress. At a physiological level, drought stress prevention mechanisms are aimed at balancing water absorption and loss. The two prevention mechanisms that favour the absorption of water are enhanced root growth and the accumulation of solutes to reduce the water potential in the tissues. Plants accumulate different types of organic and inorganic solutes in the cytosol, such as proline, sucrose, and glycine betaine, to lower cellular osmotic potential, thereby maintaining cell turgor and improving water uptake from the drying soil $[6,7]$. In particular, proline acts not only as an excellent osmolyte but also as a metal chelator, an antioxidant, and a signalling molecule [8]. On the other hand, mechanisms enhancing stomatal closure, the reduction of shoot growth, and the acceleration of leaf senescence are triggered to limit the water loss [9]. These mechanisms reduce transpiration rates, which negatively influences the absorption of $\mathrm{CO}_{2}$ [10]. A common effect of water stress is the alteration of the balance between the generation and quenching of reactive oxygen species (ROS) [11]. Increased ROS levels can cause lipid peroxidation, protein denaturation, DNA mutations, and various types of cellular oxidative damage. During water stress, both non-enzymatic (e.g., ascorbate and glutathione) and enzymatic (e.g., superoxide dismutase and catalase) antioxidant systems are activated in plant species [11]. In addition, flavonoids and hydroxycinnamates, two important classes of phenylpropanoids, are produced by plants during stress for their role in ROS scavenging [11].

Water stress significantly affects intra-cellular hormone contents [12,13]. Abscisic acid (ABA) plays a prominent role in the response to water stress, mediating the crosstalk among phytohormones and other signalling pathways [14]. Although ABA is the most characterized drought-responsive hormone, the role of jasmonate and ethylene in the water stress response is emerging [13]. The crosstalk between the different plant hormones results in synergetic or antagonistic interactions that play crucial roles in the water stress response [14].

At a molecular level, the expression of many genes is modulated by water stress conditions, and recent studies elucidated the mechanisms of drought response in plants $[15,16]$. These genes encode for proteins with a regulatory/modulation function on gene expression (e.g., transcription factors (TFs), protein kinases, and other proteins involved in signal transduction), and proteins and enzymes with a direct role in protecting cell structures, such as (i) late embryogenesis abundant (LEA) proteins and chaperones, which stabilize cellular components during abiotic stress; (ii) detoxifying enzymes involved in the protection from oxidative damage (e.g., superoxide dismutase, catalase, and glutathione peroxidase); (iii) enzymes for the synthesis of osmoprotectants (e.g., proline, glycine-betaine, soluble sugars, and trehalose). The accumulation of these functional metabolites activates tolerance mechanisms like ROS-scavenging and osmotic adjustment in the whole plant $[8,11]$. ABA is a master regulator of this complex gene regulatory network. Two principal stress response mechanisms, the ABA-dependent and the ABA-independent signalling pathways, were first discovered in Arabidopsis thaliana [15] and characterized in crops, including

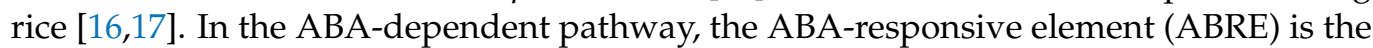
major cis-element for $\mathrm{ABA}$-responsive gene expression. ABRE-binding factors (ABFs) are bZIP-type TFs that control gene expression in an ABA-dependent manner [16]. On the other hand, analysis of the promoter regions of genes showing ABA-independent expression in stress responses and tolerance has shown the presence of the DRE cis-element. AP2/ERF TFs were identified as DRE-binding factors (DREB), which specifically interact with the DRE sequence and control the expression of a large number of stress-responsive genes [16]. In addition to the DREB and ABF regulons, the NAM-ATAF1/2-CUC2 (NAC) regulon plays a major role in the transcriptional network of the dehydration response, and 
stress-responsive NAC (SNAC) TFs are involved in abiotic stress tolerance [18]. Other TF families have been extensively reported to be involved in drought response, including the APETALA2/Ethylene-responsive element-binding protein (AP2/EREBP) [19], basic leucine zipper (bZIP) [20], MYB [21], WRKY [22], and zinc finger [23] TFs. Research advances have elucidated the role of molecular/cellular signalling networks in drought response due to a strong interconnection of signals from hub TFs, MAPK pathways, ROS, and lipid-derived pathways [24].

While knowledge about the complex mechanisms regulating drought tolerance in plants has significantly improved lately, the development of water-saving and droughttolerant cereal crops to cope with water shortage and impending demand for food production still remains extremely challenging. This is mostly due to the fact that drought tolerance is a complex trait controlled by a large group of genes, and is strongly influenced by genotype and environmental interactions $[25,26]$. In recent years, transcriptomic studies comparing genotypes with contrasting drought-response phenotypes (sensitive vs. tolerant) have been performed in many cereal species [27-33]. The use of contrasting genotypes allows for discriminating the genes and pathways that are effective for drought tolerance. Comparative transcriptomics allows for the exploitation of the natural variation present in genotypes worldwide, also analysing the ecotypes better adapted to sub-optimal environments. The genes that are differentially regulated between the drought-tolerant and the drought-sensitive genotypes can be putative candidates for further characterizations and allele mining, and to discover novel alleles for breeding programs. The huge availability of transcriptomic data promotes the use of comparative meta-analyses, allowing for the investigation of the effects of the same environmental cue across different studies. This approach is very useful for dissecting metabolic and regulatory pathways related to stress tolerance [34-37].

Here, we performed a comparative transcriptomic meta-analysis related to four Gramineae species, i.e., Brachypodium (Brachypodium distachyon L.), barley (Hordeum vulgare L.), rice (Oryza sativa L.), and maize (Zea mays L.), using RNA-Seq data available in public repositories. The aim of this study was to identify genes that are key players for improving drought tolerance as well as upstream TFs involved in the regulation of these genes.

\section{Results}

\subsection{Selection of RNA-Seq Datasets for Meta-Analysis}

To identify the genes that may represent key players for conferring drought tolerance in different Gramineae species, a transcriptomic meta-analysis was performed starting with published datasets with comparable characteristics. Four datasets that were developed from four different species were selected-Brachypodium (B. distachyon) [30], barley (H. vulgare) [29], maize (Z. mays) [31], and rice (O. sativa) [32]. The four experiments aimed to characterize the transcriptomic responses of two contrasting genotypes (one tolerant and one sensitive) to drought stress. In these experiments similar growth conditions and stress treatments were adopted, as described in detail in Section 4.1, and the total RNA was extracted from the leaves of the stressed and non-stressed plants of sensitive and tolerant accessions at the vegetative stage, and subsequently sequenced. Table 1 summarizes the main features of the materials used for this study.

The overall workflow from data mining to the identification of candidate genes is displayed in Figure 1. 
Table 1. Main features of RNA datasets used for meta-analysis. References, cultivars, biological replicates, drought stress modalities, sequencing techniques, and accessions from online repository BioProject were reported.

\begin{tabular}{ccccc}
\hline & B. distachyon & H. vulgare & O. sativa & Z. mays \\
\hline Reference & {$[30]$} & {$[29]$} & {$[32]$} & {$[31]$} \\
Sensitive accession & KOZ1 & Scarlett & HanFengB & MO17 \\
Tolerant accession & ABR8 & SBCC073 & HuHuan2B & YE8112 \\
Biological replicates & 3 & 3 & Pooled & $2-3$ \\
Drought time & 8 days & 30 days & 20 days & 7 days \\
Sequencer & HiSeq 2000 & HiSeq 2000 & HiSeq 2500 & Hiseq Xten \\
Reads length & 100 nt paired-end & 101 nt paired-end & 126 nt paired-end & 150 nt single-end \\
BioProject accession & PRJNA524106 & PRJEB12540 & PRJNA306542 & PRJNA397964 \\
\hline
\end{tabular}

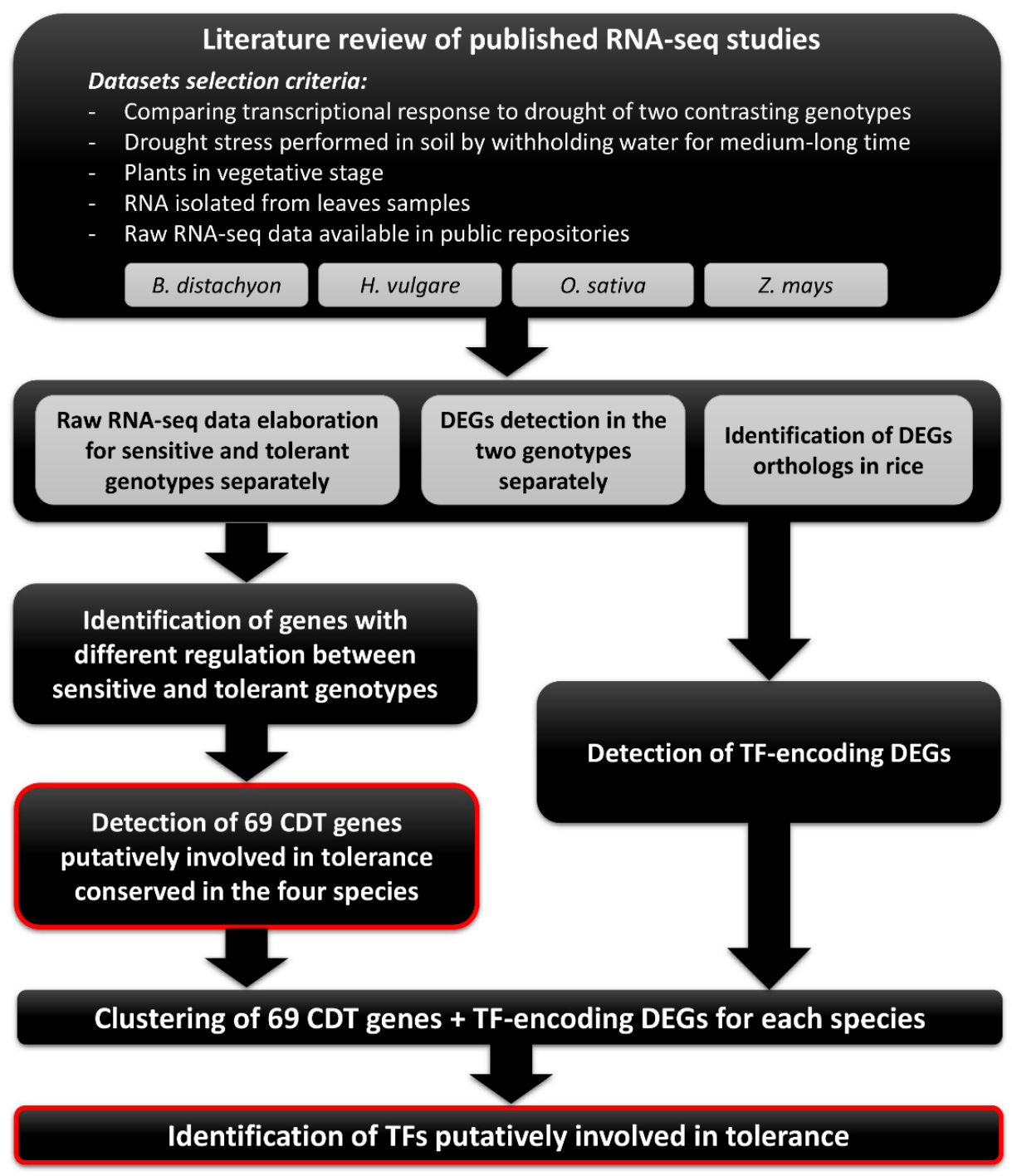

Figure 1. Overall workflow used in this study for the identification of genes putatively involved in drought tolerance in cereal crops, as well as upstream transcription factors involved in their regulation. CDT genes: Conserved Drought-tolerance Related genes.

\subsection{RNA-Seq Data Processing and Differential Expression Analyses}

Briefly, after assessing the high quality of the RNA reads, adapters and low-quality reads were filtered out, resulting in a percentage of "survived" reads of about $88 \%$ for rice, $82-91 \%$ for maize, $95-97 \%$ for barley, and 99\% for Brachypodium datasets (Table S1). For 
each RNA library, 84-97\% of filtered reads aligned to the respective reference genome assembly (Table S1), and the number of reads mapping to each predicted gene was estimated.

Differential expression analyses of stressed vs. control samples for both tolerant and sensitive accessions were carried out (Supplementary File S1, Figure S1). The number of up- and down-regulated differentially expressed genes (DEGs) for each analysis, along with the number of active genes, is summarised in Table 2.

In rice, the two contrasting genotypes displayed a similar number of DEGs. In contrast, the tolerant genotypes of Brachypodium and maize showed a lower number of DEGs compared to the sensitive ones, whereas in barley, the tolerant genotype showed a higher number of DEGs than the sensitive one.

Table 2. Numbers of predicted genes in the reference assembly for each species, of active genes and of down- and up-regulated DEGs for each experiment.

\begin{tabular}{ccccccccc}
\hline & \multicolumn{2}{c}{ B. distachyon } & \multicolumn{2}{c}{ H. vulgare } & \multicolumn{2}{c}{ O. sativa } & \multicolumn{2}{c}{ Z. mays } \\
\cline { 2 - 9 } & Sensitive & Tolerant & Sensitive & Tolerant & Sensitive & Tolerant & Sensitive & Tolerant \\
\hline Predicted genes & 35,118 & 35,118 & 43,050 & 43,050 & 39,978 & 39,978 & 45,953 & 45,953 \\
Active genes & 19,404 & 18,411 & 16,092 & 15,773 & 18,449 & 18,285 & 20,094 & 21,048 \\
\hline Down-reg DEGs & 3551 & 61 & 287 & 1261 & 1634 & 1360 & 2915 & 583 \\
Up-reg DEGs & 3145 & 234 & 448 & 653 & 1650 & 1134 & 2129 & 348 \\
\hline Total DEGs & 6696 & 295 & 735 & 1914 & 3284 & 2494 & 5044 & 931 \\
\hline
\end{tabular}

The DEGs of each species were then mapped to the rice predicted genes to obtain comparable datasets. For each genotype, the number and percentage of DEGs orthologous to the rice genes are shown in Table S2.

\subsection{Comparison of the Level of Drought Stress among the Four Datasets}

We used the four datasets derived from the rice orthology analysis to evaluate the comparability of the drought treatments imposed on the plants in the considered experiments. First, we compared the DEGs among the four experiments, considering all the genes that were differentially expressed in at least one genotype of each experiment. A total of 142 DEGs common among the four experiments was found (Table S3). Then, we referred to the paper by Todaka et al. [38] to evaluate the drought severity of the four treatments. The authors analysed the physiology, gene expression, and metabolic changes in rice plants at the vegetative stage subjected to drought treatments with different intensities. In particular, the moderate level 3 treatment (called Md3 in [38]) caused stomatal closure and shoot growth retardation, while the severe drought treatment (called Sds in [38]) also resulted in leaves wilting and photosynthesis inhibition. We compared the rice DEGs under the Sds treatments from Todaka et al. with the DEGs of the four selected datasets, considering the orthology of the rice genome for Brachypodium, barley, and maize. A total of 1377, 407, 1242, and 1140 DEGs resulted between the Sds treatment [38] and the considered experiments of Brachypodium, barley, maize, and rice, respectively. In addition, 65 out of the 142 common DEGs among the four experiments (Table S3) were differentially expressed under the Sds treatment [38]. Therefore, the transcriptomic response of the plants analysed in the four selected experiments was consistent with a severe condition of drought stress.

\subsection{Identification of Genes Involved in Tolerance to Drought Stress in each Species}

We assumed that the genes putatively involved in the tolerant response to drought are the ones whose expression regulation differs between sensitive and tolerant accessions during the drought treatment, as previously reported by Buti et al. [35]. Then, we classified the DEGs putatively involved in drought tolerance in eight classes, according to the $\log _{2}$ (Fold Change) (LFC) difference between the sensitive and tolerant genotypes of the DEGs, as follows: (i) genes up-regulated in the sensitive genotype and unchanged in the tolerant one ("sen+"); (ii) genes down-regulated in the sensitive genotype and unchanged in the 
tolerant one ("sen-"); (iii) genes up-regulated in the tolerant genotype and unchanged in the sensitive one ("tol+"); (iv) genes down-regulated in the tolerant genotype and unchanged in the sensitive one ("tol-"); (v) genes differentially expressed in both genotypes, showing a difference of LFC (LFC of tolerant sample-LFC of sensitive sample) higher than 1 (" $\triangle$ LFC $>1$ "); (vi) genes differentially expressed in both genotypes, showing a difference of LFC lower than -1 (" $\triangle \mathrm{LFC}<-1$ "); (vii) genes down-regulated in the sensitive genotype and up-regulated in the tolerant one ("sen-/tol+"); (viii) genes up-regulated in the sensitive genotype and down-regulated in the tolerant one ("sen+/tol-"). The complete classification is reported on Supplementary File S2. The numbers of genes belonging to the eight classes are summarized in Table 3.

Table 3. Genes putatively involved in the tolerant response to drought stress. The numbers of genes belonging to the eight classes were reported for each dataset.

\begin{tabular}{ccccc}
\hline Class & B. distachyon & H. vulgare & O. sativa & Z. mays \\
\hline sen+ & 3125 & 313 & 942 & 2026 \\
sen- & 3340 & 168 & 901 & 2722 \\
tol+ & 38 & 543 & 421 & 251 \\
tol- & 26 & 1117 & 632 & 384 \\
$\Delta$ LFC $>1$ & 16 & 12 & 88 & 56 \\
$\Delta$ LFC $<-1$ & 4 & 13 & 40 & 9 \\
sen - tol+ & 185 & 1 & 19 & 77 \\
sen+/tol- & 9 & 26 & 14 & 83 \\
\hline TOTAL & 6743 & 2193 & 3057 & 5608 \\
\hline
\end{tabular}

Among these genes, 5337 Brachypodium genes (79.15\%), 1557 barley genes $(71 \%)$, and 4723 maize genes $(84.22 \%$ ) displayed a putative ortholog in the rice genome (Table S4).

\subsection{Identification of Genes Involved in Tolerance to Drought Stress across Multiple Species}

To identify conserved genes involved in drought tolerance across multiple species, the IDs of the rice orthologous genes, previously identified and reported in Table S4, were compared among the four datasets. We identified 69 genes that were present in all of the four species (Table S5) (hereafter referred to as CDT genes). Considering rice as the most characterized species, several CDT genes are known to be involved in specific cell functions (Table 4).

Table 4. Rice Conserved drought tolerance-related (CDT) genes. Where defined, the gene names and the pathways in which these genes are involved are shown.

\begin{tabular}{|c|c|c|c|}
\hline n. & RAP ID & Gene Name & Related Pathway \\
\hline Os_1 & Os01g0111100 & \multicolumn{2}{|c|}{ uncharacterized gene } \\
\hline Os_2 & Os01g0117300 & OsRLCK17 & signalling \\
\hline Os_3 & Os01g0227800 & \multicolumn{2}{|c|}{ uncharacterized gene } \\
\hline Os_4 & Os01g0551000 & \multicolumn{2}{|c|}{ uncharacterized gene } \\
\hline Os_5 & Os01g0639900 & OsCA1 & PHOTOSYNTHESIS ( $\mathrm{CO}_{2}$ fixation) \\
\hline Os_6 & Os01g0733500 & RD22 & ABIOTIC STRESS RESPONSE \\
\hline Os_7 & Os01g0803200 & OsCYS1 & cysteine proteinase inhibitors \\
\hline Os_8 & Os02g0101500 & \multicolumn{2}{|l|}{ Peroxisomal hydroxypyruvate reductase } \\
\hline Os_9 & Os02g0465900 & ChaC-like & TRANSPORT \\
\hline Os_10 & Os02g0626400 & PAL2-2 & SECONDARY METABOLISM \\
\hline Os_11 & Os02g0710900 & HSP70—OsBiP & ABIOTIC STRESS RESPONSE \\
\hline Os_12 & Os02g0744000 & \multicolumn{2}{|c|}{ uncharacterized gene } \\
\hline Os_13 & Os02g0783625 & \multicolumn{2}{|c|}{ lysine ketoglutarate reductase } \\
\hline Os_14 & Os02g0815700 & \multicolumn{2}{|c|}{ uncharacterized gene } \\
\hline Os_15 & Os03g0114800 & OsCd1 & TRANSPORT \\
\hline Os_16 & Os03g0129300 & G3PDH & PHOTOSYNTHESIS (Calvin Cycle) \\
\hline Os_17 & Os03g0192700 & Inositol-3-phosphate synthase 1 & \\
\hline
\end{tabular}


Table 4. Cont.

\begin{tabular}{|c|c|c|c|}
\hline n. & RAP ID & Gene Name & Related Pathway \\
\hline Os_18 & Os03g0238300 & \multicolumn{2}{|l|}{ inositol-1,4,5-trisphosphate 5-phosphatase } \\
\hline Os_19 & Os03g0336000 & \multicolumn{2}{|c|}{ uncharacterized gene } \\
\hline Os_20 & Os03g0592500 & $L H C B$ & PHOTOSYNTHESIS (photosystem assembly) \\
\hline Os_21 & Os03g0700700 & OsLOX8 & JA SIGNALLING \\
\hline Os_22 & Os03g0744700 & \multicolumn{2}{|c|}{ uncharacterized gene } \\
\hline Os_23 & Os03g0844900 & \multicolumn{2}{|c|}{ uncharacterized gene } \\
\hline Os_24 & Os03g0849800 & \\
\hline Os_25 & Os03g0850400 & \multicolumn{2}{|l|}{ aspartate kinase } \\
\hline Os_26 & Os04g0234600 & SBPase & PHOTOSYNTHESIS (Calvin Cycle) \\
\hline Os_27 & Os04g0390100 & OsHIPP29 & TRANSPORT \\
\hline Os_28 & Os04g0414700 & PsaO & PHOTOSYNTHESIS (photosystem assembly) \\
\hline Os_29 & Os04g0459500 & G3PDH & PHOTOSYNTHESIS (Calvin Cycle) \\
\hline Os_30 & Os04g0496000 & \multicolumn{2}{|c|}{ uncharacterized gene } \\
\hline Os_31 & Os04g0508800 & \multicolumn{2}{|c|}{ uncharacterized gene } \\
\hline Os_32 & Os04g0618200 & \multicolumn{2}{|c|}{ UDP-arabinose 4-epimerase 2} \\
\hline Os_33 & Os05g0186300 & OsNADP-ME3 & PHOTOSYNTHESIS (Calvin Cycle) \\
\hline Os_34 & Os05g0429500 & Dienelactone hydrolase & \\
\hline Os_35 & Os05g0439400 & OsPUB44 & E3 ubiquitin ligase \\
\hline Os_36 & Os05g0453300 & \multicolumn{2}{|c|}{ uncharacterized gene } \\
\hline Os_37 & Os05g0468900 & \multicolumn{2}{|c|}{ uncharacterized gene } \\
\hline Os_38 & Os05g0501700 & \multicolumn{2}{|c|}{ uncharacterized gene } \\
\hline Os_39 & Os05g0535900 & \multicolumn{2}{|c|}{ IQ calmodulin-binding motif family protein } \\
\hline Os_40 & Os06g0129400 & OsSPX-MFS3 & CELLULAR TRANSPORT \\
\hline Os_41 & Os06g0486800 & FDH (Formate dehydrogenase) & CELLULAR TRANSPORT \\
\hline Os_42 & Os06g0528600 & Aminopropyl transferase & \\
\hline Os_43 & Os06g0716000 & \multicolumn{2}{|c|}{ uncharacterized gene } \\
\hline Os_44 & Os07g0148900 & Psak & PHOTOSYNTHESIS (photosystem assembly) \\
\hline Os_45 & Os07g0524900 & \multicolumn{2}{|c|}{ uncharacterized gene } \\
\hline Os_46 & Os08g0104600 & OsFd1 & OXIDATIVE STRESS RESPONSE \\
\hline Os_47 & Os08g0141300 & OsVST1 & root system architecture \\
\hline Os_48 & Os08g0141400 & \multicolumn{2}{|c|}{ NADH-ubiquinone oxidoreductase } \\
\hline Os_49 & Os08g0364900 & \multicolumn{2}{|c|}{ uncharacterized gene } \\
\hline Os_50 & Os08g0434300 & \multicolumn{2}{|l|}{ malate dehydrogenase } \\
\hline Os_51 & Os08g0485900 & \multicolumn{2}{|c|}{ uncharacterized gene } \\
\hline Os_52 & Os08g0508800 & OsHI-LOX & JA SIGNALLING \\
\hline Os_53 & Os09g0294000 & \multicolumn{2}{|l|}{ Aspartate kinase-homoserine dehydrogenase } \\
\hline Os_54 & Os09g0297000 & \multicolumn{2}{|l|}{ Ferrochelatase-1 } \\
\hline Os_55 & Os09g0426800 & OsGL1-1 & leaf wax synthesis \\
\hline Os_56 & Os09g0438000 & OsNOX7 & OXIDATIVE STRESS RESPONSE \\
\hline Os_57 & Os09g0438100 & unchar & terized gene \\
\hline Os_58 & Os09g0532000 & SGR & LEAF SENESCENCE \\
\hline Os_59 & Os10g0462900 & OsHsp60-1 & ABIOTIC STRESS RESPONSE \\
\hline Os_60 & Os10g0502400 & OsHEMA & LEAF SENESCENCE \\
\hline Os_61 & Os10g0516100 & OsGDCH & LEAF SENESCENCE \\
\hline Os_62 & Os10g0530500 & glutathione S-transferase & OXIDATIVE STRESS RESPONSE \\
\hline Os_63 & Os11g0145200 & Indole-3-acetate beta-glucosyltransferase & AUXIN SIGNALLING \\
\hline Os_64 & Os11g0455500 & OsSAHH & SECONDARY METABOLISM \\
\hline Os_65 & Os11g0520500 & unchar & terized gene \\
\hline Os_66 & Os12g0115700 & $\mathrm{CHI}$ & SECONDARY METABOLISM \\
\hline Os_67 & Os12g0420200 & CSP $41 b$ & OXIDATIVE STRESS RESPONSE \\
\hline Os_68 & Os12g0428000 & glycosyl hydrolase & \\
\hline Os_69 & Os12g0534100 & unchar & terized gene \\
\hline
\end{tabular}

As expected, some CDT genes are known to be involved in the abiotic stress response, including the ABA-responsive gene RD22 (Os01g0733500) [39], and two heat shock proteinencoding genes (HSPs), HSP70 (Os02g0710900 [40]), and OsHsp60-1 (Os10g0462900). Several genes play a role in different photosynthesis-related processes. Three genes are involved in the assembly of photosystems. Os03g0592500 encodes a light-harvesting 
chlorophyll-binding protein (LHCB) of the photosystem II;Os04g0414700 and Os07g0148900 encode the photosystem I subunits $\mathrm{O}$ (PsaO) and K (PsaK) [41], respectively. The gene Os01g0639900 codes for a carbonic anhydrase 1 (OsCA1), involved in $\mathrm{CO}_{2}$ fixation in RuBP through Rubisco activity [42]. Some genes are involved in the Calvin cycle. Os04g0459500 and Os03g0129300 code for glyceraldehyde-3-phosphate dehydrogenases (G3PDH), Os04g0234600 codes for a sedoheptulose 1,7-bisphosphatase (OsSBP), and Os05g0186300 codes for the NADP-dependent malic enzyme OsNADP-ME3. This enzyme catalyses the oxidative decarboxylation of malate and $\mathrm{NADP}^{+}$in the chloroplast, releasing $\mathrm{CO}_{2}$, which is then utilized in the Calvin cycle [43]. Other genes are involved in leaf senescence, including the stay-green rice gene (OsSGR, Os09g0532000), a chlorophyll-degrading $\mathrm{Mg}^{++}$-dechelatase [44-46]. The gene OsHemA1 (Os10g0502400), a glutamyl-tRNA reductase involved in the initial steps of chlorophyll synthesis [47], and the gene OsGDCH (glycine decarboxylase complex H subunit, Os10g0516100) is involved in leaf senescence [48]. Two gene codes for chloroplast proteins that play important roles in oxidative stress protection are OsFd1 (Os08g0104600), a ferredoxin that mediates electron transfer and probably regulates the expression of plastidial genes in a redox-dependant manner [49], and CSP41b (Os12g0420200), an $\mathrm{NAD}^{+}(\mathrm{P})$-binding protein which is required for normal leaf colour and chloroplast morphology [50]. In addition, OsNOX7 (Os09g0438000) codes for an NADPH oxidase-respiratory burst oxidase homologue (RBOH) protein [51]. Three genes are involved in secondary metabolism, including the upstream PAL2-2 gene (Os02g0626400) [52], the S-adenosylhomocysteine hydrolase gene (OsSAHH, Os11g0455500), which is involved in lignin biosynthesis [53], and the chalcone-flavonone isomerase (CHI, Os12g0115700), which is involved in flavonoid biosynthesis [54]. Three genes are involved in hormone signalling. Os08g0508800 and Os03g0700700 code for two lipoxygenases (OsHI-LOX and OsLOX8, respectively), are involved in jasmonic acid (JA) biosynthesis, and are important players in the JA signalling pathway [55,56], while Os11g0145200, coding for an indole-3-acetate beta-glucosyltransferase, is putatively involved in auxin signalling [57]. Five genes (Os02g0465900, Os03g0114800, Os04g0390100, Os06g0129400, and Os06g0486800) are probably involved in cellular transport. Finally, twenty CDT genes have not been characterized yet (Table 4).

\subsection{Principal Component Analysis and Protein-Protein Interaction of CDT Genes}

To investigate whether the expression profiles of the CDT genes could intercept the differences between tolerant and sensitive genotypes, we performed a principal component analysis (PCA) for each dataset using the expression data of the CDT genes (Figure 2).

In Brachypodium (Figure 2A), the first PCA component (Dim1) accounted for $67.3 \%$ of the variance, clearly separating the stressed sensitive samples from the other ones. The second component (Dim2) captured a variance of $11 \%$, differentiating the control sample of the sensitive genotype from the other ones. Gene expression of the CDT genes was very similar in stressed and control samples of the B. distachyon tolerant genotype. In barley (Figure 2B), Dim 1 (39.3\%) separated stressed samples from the control ones independently from the genotype, whereas Dim2 $(26.5 \%)$ separated the stressed samples of the tolerant genotype from all the others. A similar situation was observed in rice (Figure 2C), where the first component $(54.7 \%)$ clearly separated the stressed from the control samples of both genotypes, whereas Dim2 (27.6\%) intercepted the differences in control samples between tolerant and susceptible genotypes. In maize (Figure 2D), Dim1 (50.9\% of the variance) separated the samples of the tolerant genotype from those of the sensitive genotype. Dim2 (32.4\% of the variance) clearly separated the control samples from the stressed ones in the susceptible genotypes, while not clearly separating the stressed and control samples of the tolerant genotype. 
A

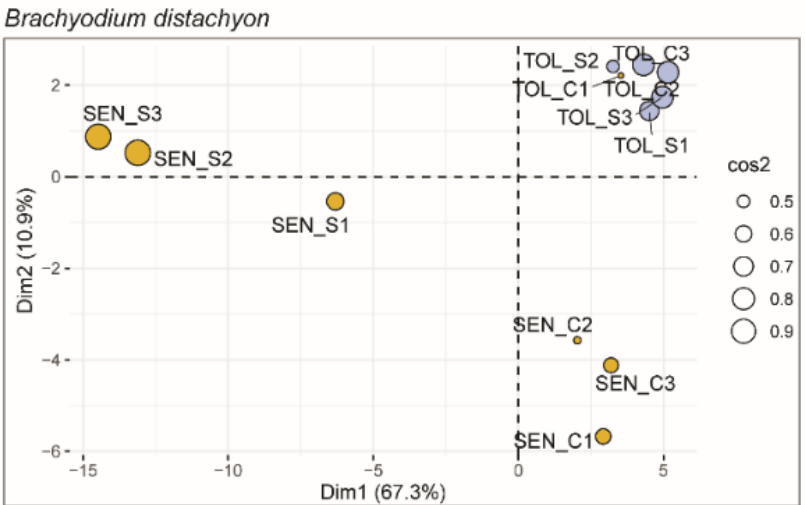

C

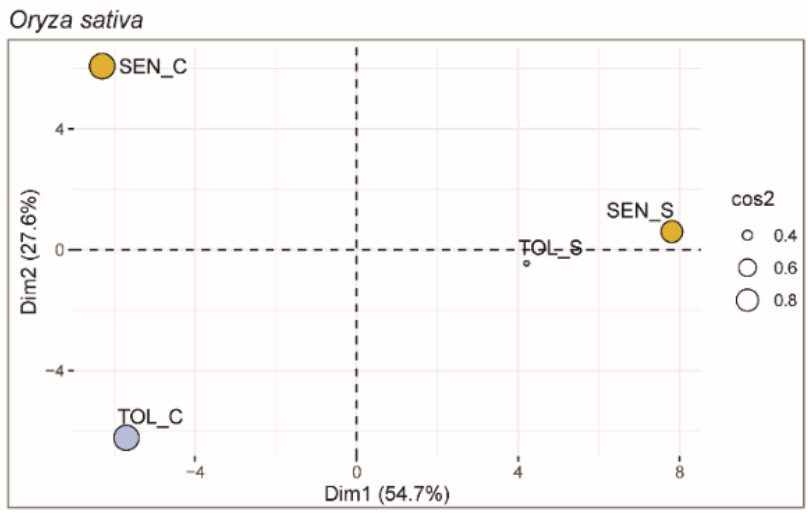

B

Hordeum vulgare

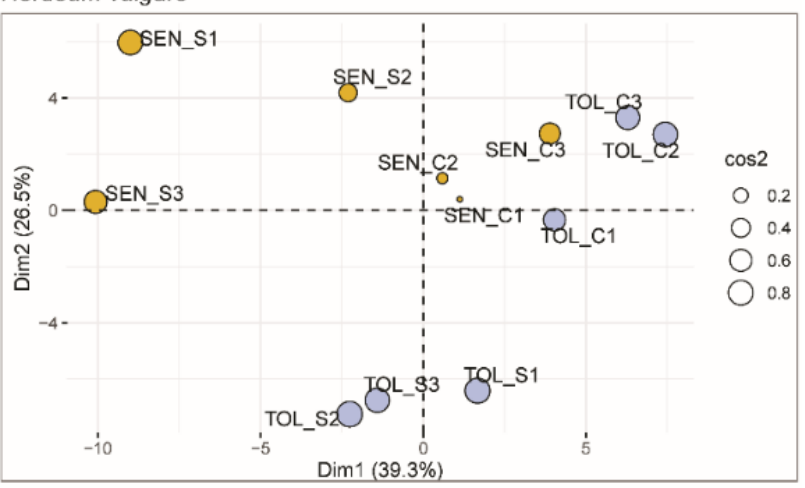

D

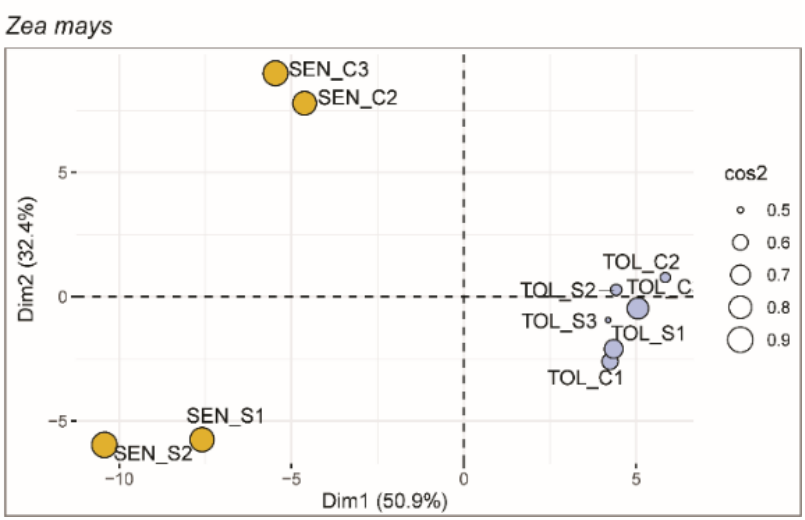

Figure 2. Principal component analysis (PCA) biplots of the four RNA-Seq datasets using the TPM expression values of the CDT genes of B. distachyon (A), H. vulgare (B), O. sativa (C), and Z. mays (D). Samples from the sensitive genotypes are in yellow, whereas those from the tolerant genotypes are in light blue. Squared cosine (cos2) indicates the contribution of each sample to a given observation; the bigger the circle is, the higher the contribution is. TOL_C: biological replicates of the tolerant genotypes that were used as non-stressed control in the experiments; TOL_S: biological replicates of the tolerant genotypes under drought stress; SEN_C: biological replicates of the sensitive genotypes that were used as non-stressed controls; SEN_S: biological replicates of the sensitive genotypes under drought stress.

A protein-protein interaction (PPI) network using the 69 rice CTD genes revealed that 23 proteins showed at least one interaction (Figure 3 ).

A principal network of 12 proteins that interacted with each other was identified. This main network included the three photosystem-related proteins PsaK (OsJ_23098), PsaO (OsJ_14748), and LHCB (RCABP89), which were strongly interconnected with each other, the two G3PDHs (OsJ_15048 and OsJ_09272), OsFd1 (ADI1), CSP41b (OsJ_35887), OsGDCH (GDCSH), and the protein Os03g0844900 (OS03T0844900-01). Moreover, the two LOX proteins (OsJ_12241, CM-LOX1) and the two HSPs (OS02T0710900-01, OsJ_31804) constituted two independent networks.

\subsection{Clustering Gene Expression to Find Common Patterns and Associated Transcription Factors}

To identify putative upstream regulators of the differentiation between tolerant and sensitive responses, we selected the TF-encoding DEGs of the four species (Supplementary File S3) and we performed a k-means cluster analysis of the gene expression profiles of the CDT genes together with the TF-DEGs for each species. The optimum cluster number was determined based on converging results of the sum of squared errors (SSE) estimate and the Calinsky criterion, as described by Testone et al. [58]. The analysis defined the presence of four different expression clusters for each species (Figure 4, Supplementary File S4). 


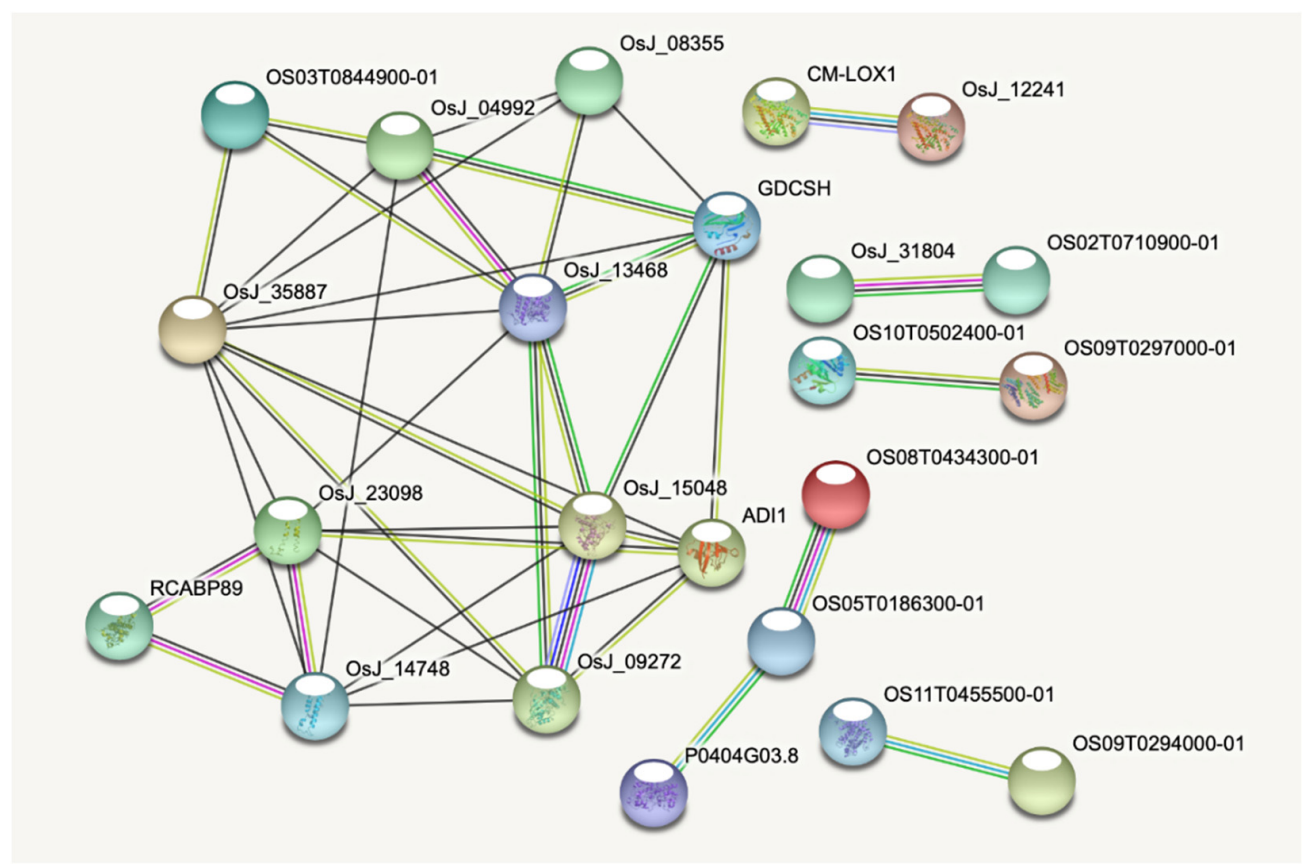

Figure 3. Protein-protein interaction (PPI) network using the 69 rice proteins. Only proteins involved in interactions with a high confidence (combined score higher than 0.7) were shown. For each shown protein, the related rice gene ID is indicated in parentheses: OS03T0844900-01 (Os03g0844900); OsJ_04992 (Os02g0101500); OsJ_08355 (Os02g0744000); OsJ_35887 (Os12g0420200); OsJ_13468 (Os04g0234600); GDCSH (Os10g0516100); OsJ_23098 (Os07g0148900); OsJ_15048 (Os04g0459500); ADI1 (Os08g0104600); RCABP89 (Os03g0592500); OsJ_14748 (Os04g0414700); OsJ_09272 (Os03g0129300); CM-LOX1 (Os08g0508800); OsJ_12241 (Os03g0700700); OsJ_31804 (Os10g0462900); OS02T0710900-01 (Os02g0710900); OS10T0502400-01 (Os10g0502400); OS09T0297000-01 (Os09g0297000); OS08T0434300-01 (Os08g0434300); OS05T0186300-01 (Os05g0186300); P0404G03.8 (Os06g0486800); OS11T0455500-01 (Os11g0455500); OS09T0294000-01 (Os09g0294000).

Differences in gene expression behaviour between sensitive and tolerant genotypes were highlighted by the cluster profiles. In addition, some clusters were strongly negatively correlated, including cluster 1 and cluster 2 in Brachypodium $(r=-0.98)$ (Figure 4A), cluster 1 and 2 in barley ( $\mathrm{r}=-0.94)$ (Figure 4B), cluster 1 and 3 in rice $(r=-0.9)$ (Figure $4 \mathrm{C})$, and cluster 2 and 4 in maize $(r=-0.98)$ (Figure 4D). The CDT genes showed a peculiar cluster distribution in each species, but some similarities were detected; in Brachypodium, barley, and rice, the photosynthetic genes $P s a O, P s a K, L H C B$, and CA1 clustered together (green arrows in Figure 4). Similarly, in maize, the genes $P s a O, L H C B$, and $C A 1$ belonged to cluster 4, whereas PsaK clustered separately in cluster 3 . Interestingly, in each species, the cluster harbouring the photosynthesis-related genes (cluster 2 in Brachypodium, barley, and rice, and cluster 4 in maize) was strongly negatively correlated with the cluster containing the homologue gene of rice SGR (brown arrows in Figure 4).

We then focused on the TF-encoding genes belonging to the two negatively correlated clusters related to photosynthesis and SGR to identify possible TFs with a regulatory role in the drought-tolerant response. In the selected clusters, we detected 265, 51, 84, and 142 TF-encoding genes for Brachypodium, barley, rice, and maize, respectively (Supplementary File S5). Most of these genes belonged to the eight classes previously defined (264, 42, 70, and 141 for Brachypodium, barley, rice, and maize, respectively). The distribution of the principal TF families in the two negatively correlated species of the four species is shown in Figure S2. The analysis highlighted that several TF families (AP2, ARF, bHLH, bZIP, C3H, DBB, ERF, G2-like, HD-ZIP, HSF, MYB, and NAC) were represented in the two negatively correlated clusters of all four species, and genes belonging to the bHLH, bZIP, MYB, and NAC families were the most abundant. 


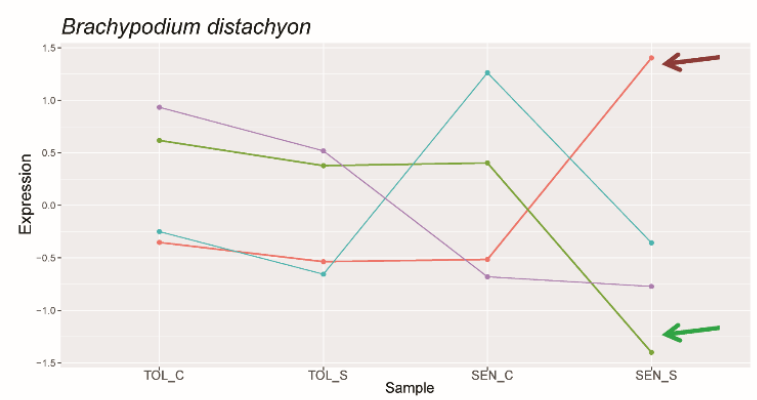

C

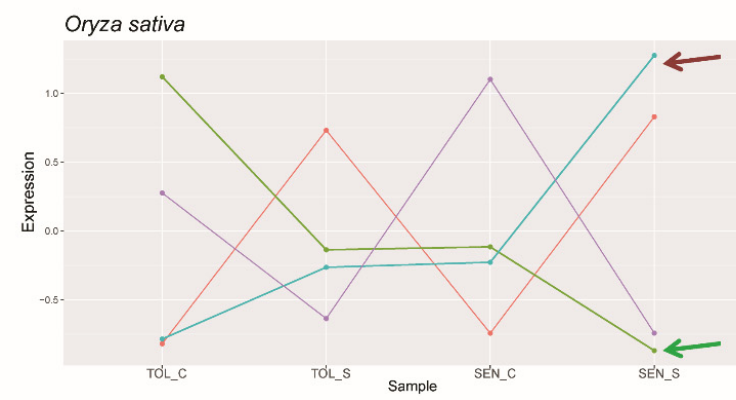

B

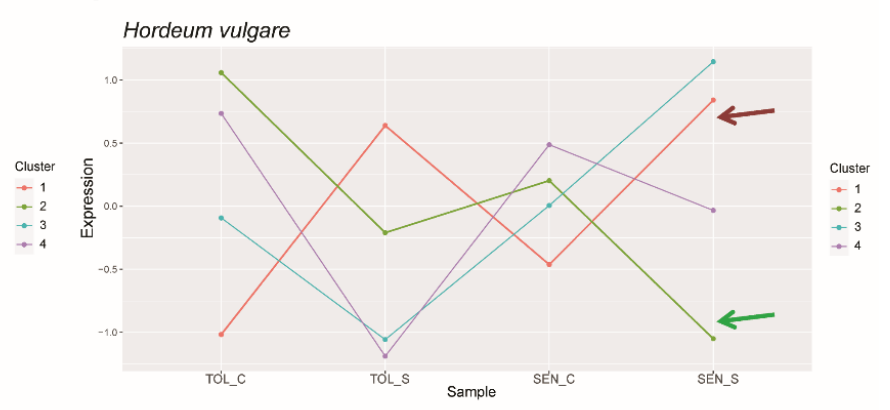

D

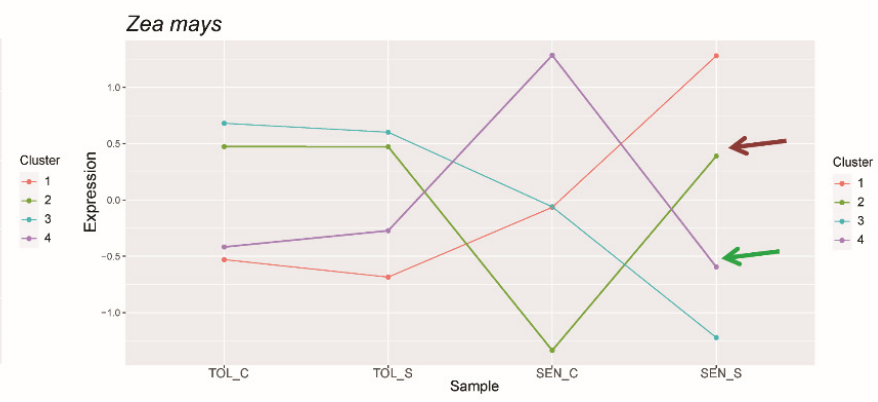

Figure 4. K-means cluster analysis of gene expression of TF-encoding DEGs and CDT genes in the four cereal datasets. Distance matrix for k-means clustering was calculated by Euclidean similarity measurement and using centred Pearson's correlation as the distance metric, resulting in four gene clusters for each species: B. distachyon (A), H. vulgare (B), O. sativa (C), and Z. mays (D). Expression refers to log2+1 normalized TPM values that were then scaled to identify clusters of genes that share similar expression profiles rather than similar expression levels. The lines in the cluster plots represent the centroids in each cluster, around which genes with similar expression profiles are associated. The negatively correlated clusters harbouring SGR genes or photosynthesis-related genes (the genes CA1/PsaO/PsaK/LHCB for Brachypodium, barley, and rice, the genes $C A 1 / P s a O / / L H C B$ for maize) are indicated by brown or green arrows, respectively. TOL_C: gene expression of tolerant genotypes that were used as non-stressed controls in the experiments; TOL_S: gene expression of tolerant genotypes under drought stress; SEN_C: gene expression of sensitive genotypes that were used as non-stressed controls; SEN_S: gene expression of sensitive genotypes under drought stress.

We used a not stringent orthology analysis (see Section 4.4 for details) to identify the similar TF-encoding genes that may share conserved functions related to drought tolerance across the four species. We detected 18 groups of DEGs coding for TFs, five of which were represented in three of the four analysed species (Table 5).

\subsection{Gene Co-Expression Network Analysis of CDT Genes and TF DEGs on an Independent Water} Stress Experiment in Rice

We focused on rice to validate these results with independent data and to find regulatory relationships between the identified CDT genes and specific families of TFs. Hence, we constructed and analysed a targeted gene co-expression network (GCN) related to the transcriptomic data of a previous experiment of PEG-mediated osmotic stress in two rice genotypes, one tolerant (Eurosis) and one sensitive (Loto) to osmotic stress [28]. In particular, the genes encoding TFs that were differentially expressed under osmotic stress in both genotypes and the 69 CDT genes were selected, for a total of 797 genes. The list of the TF-encoding genes used for the analysis and their gene expression values, together with those of the rice CDT genes, are reported in Table S6. Pairwise correlation analysis of their expression values was performed (Supplementary File S6), and significant correlations $(p$-value $<0.05)$ and absolute Pearson's correlation $(|\mathrm{r}|)$ values $\geq 0.9$ were used to develop the GCN. The Cytoscape platform [59] was used to determine the relationships among the selected genes and to identify putative upstream regulators of the genes related to photosynthesis and senescence that differentiate the tolerant from the sensitive responses. 
The data related to the network topological analysis are shown in Table S7. The GCN network included 787 out of the initial 797 genes (Figure 5A).

Table 5. Candidate TF genes related to drought tolerance across the four species.

\begin{tabular}{|c|c|c|c|c|c|}
\hline B. distachyon Gene ID & H. vulgare Gene ID & O. sativa Gene ID & Z. mays Gene ID & $\begin{array}{c}\text { Corresponding } \\
\text { Clusters }\end{array}$ & TF Class \\
\hline Bradi1g06670 & - & Os03g0782500 & $\mathrm{Zm00001d034298}$ & photosynthesis & bHLH \\
\hline Bradi2g00730 & HORVU3Hr1G000170 & Os01g0108400 & - & SGR & bHLH \\
\hline Bradi2g60970 & - & Os01g0952800 & - & photosynthesis & bHLH \\
\hline Bradi3g02730 & - & Os02g0128200 & $\begin{array}{l}\text { Zm00001d053967 } \\
\text { Zm00001d015118 }\end{array}$ & photosynthesis & bZIP \\
\hline \multirow[t]{2}{*}{ Bradi3g57960 } & - & - & Zm00001d018178 & SGR & bZIP \\
\hline & - & Os07g0644100 & Zm00001d007042 & SGR & $\mathrm{bZIP}$ \\
\hline Bradi4g02570 & - & Os12g0601800 & - & photosynthesis & $\mathrm{bZIP}$ \\
\hline Bradi1g11310 & - & - & $\begin{array}{l}\text { Zm00001d033719 } \\
\text { Zm00001d013443 }\end{array}$ & photosynthesis & CO-like \\
\hline Bradi3g35560 & - & Os08g0408500 & Zm00001d032295 & SGR & ERF \\
\hline Bradi4g29380 & - & Os09g0379600 & & SGR & HD-ZIP \\
\hline Bradi5g17170 & HORVU2Hr1G092710 & - & $\begin{array}{l}\text { Zm00001d002799 } \\
\text { Zm00001d025964 }\end{array}$ & $S G R$ & HD-ZIP \\
\hline Bradi3g16400 & - & Os08g0159500 & - & photosynthesis & LBD \\
\hline Bradi2g16120 & - & Os05g0567600 & - & photosynthesis & MYB \\
\hline Bradi3g16515 & HORVU7Hr1G070870 & - & - & photosynthesis & MYB \\
\hline Bradi3g52807 & - & - & Zm00001d017782 & photosynthesis & MYB \\
\hline- & HORVU5Hr1G099390 & - & $\mathrm{Zm00001d013151}$ & SGR & NAC \\
\hline Bradi1g60030 & - & Os03g0413000 & - & photosynthesis & NF-YB \\
\hline- & - & Os06g0145800 & Zm00001d036148 & photosynthesis & Whirly \\
\hline
\end{tabular}

A

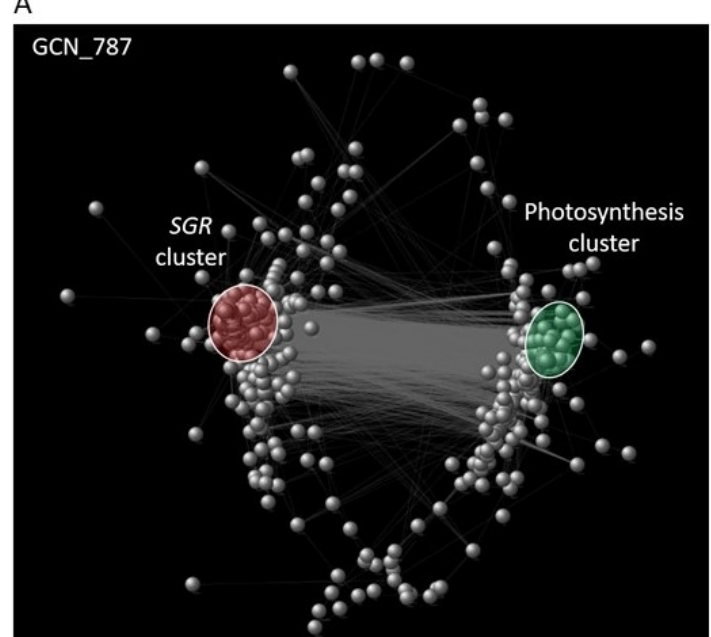

B

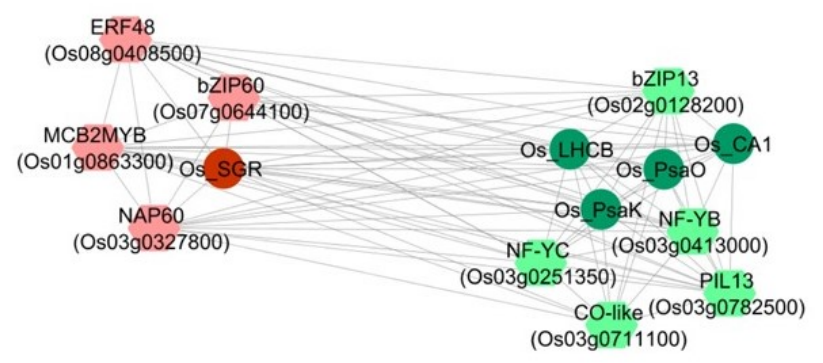

Figure 5. (A) Gene co-expression network $(\mathrm{GCN})$ created with Cytoscape related to an independent osmotic stress experiment [28]. The nodes indicate the 787 genes belonging to the network, that is, CDT genes and DEG-TFs. Grey lines represent significant $(p$-value $\leq 0.05)$ gene expression correlations higher than $|0.9|$. The two negatively correlated groups of the GCN, which correspond to the two negatively correlated clusters shown in Figure $4 \mathrm{C}$ and are related to photosynthesis genes and SGR, are highlighted in green and red, respectively. (B) Graphical representation of the principal GCN hub genes related to photosynthesis and SGR pathways that are discussed in the text. Grey lines represent significant $(p$-value $\leq 0.05)$ gene expression correlations higher than $|0.9|$. 
In the GCN, the PsaO gene had the highest number of connections (429) and formed a core subnetwork of two negatively correlated groups of genes, including 43 of the 69 CDT genes (Table S8). Among them, 26 CDT genes were positively correlated with $P s a O$ and included several genes involved in photosynthesis-PsaK, LHCB, OsCA1, and three genes involved in the Calvin cycle (the OsSBP gene Os04g0234600 and the two G3PDH genes, Os04g0459500 and Os03g0129300) found in the PPI network. Other 16 CDT genes, including SGR, were negatively correlated to $P_{s a O}$. These genes were positively correlated to SGR (Table S8), fully corroborating the k-means clustering data. Node degree, which, in a GCN network, is the number of neighbours to which a node directly connects, is an important centrality parameter that identifies essential genes in the network $[58,60]$. In this respect, the GCN analysis identified $P_{s a O}, P_{s a K}$, and $L H C B$, with node degrees of 429, 418, and 410 respectively, as hub central genes in the osmotic stress response.

Among the 84 rice TF-encoding genes belonging to the two negatively correlated clusters related to photosynthesis and SGR in the k-means cluster analysis (rice clusters 2 and 3, respectively; Supplementary File S5), 68 genes were included in the GCN. In particular, 14 TF genes in the GCN were strongly positively and negatively correlated ( $|\mathrm{r}|$ values $\geq 0.9)$ to $P S a O$ and SGR, respectively (Supplementary File S5). Amongst them, genes belonging to the nuclear factor $Y$ (NF-Y or NF-YB/NF-YC) group displayed high node degrees in the GCN and were highly co-expressed with the $P_{s a O}, P_{s a K}$, and $L H C B$ genes. A member of the CONSTANS-like (COL) TF gene family (Os03g0711100) was highly co-expressed with three NF-Y genes in the PsaO core subnetwork. Os03g0711100 showed a high betweenness centrality (BC) score in the global GCN network, which indicates a key role in the transcriptional regulatory network. On the other hand, $20 \mathrm{TF}$ genes strongly positively and negatively correlated ( $|\mathrm{r}|$ values $\geq 0.9$ ) to $S G R$ and $P s a O$, respectively (Supplementary File S5). Amongst them, genes belonging to the NAC, MYB, HSF, ERF, and bZIP families also displayed high node degrees in the GCN and were highly co-expressed with SGR.

\subsection{Analysis of TF Binding Sites on the Promoter Sequences of the Rice CDT Genes}

The 3000 bp upstream nucleotide sequences of the rice CDT genes (Table S9) were searched for the binding sites of the NF-Y, NF-CO complexes and the NAC, MYB, ERF, and bZIP TF families (Supplementary File S7). Several NF-Y and NF-CO motifs were present in the promoters of the CDT genes belonging to the photosynthesis-related cluster. The promoters of $\mathrm{PsaO}$ and $\mathrm{PsaK}$ were particularly enriched in NF-CO regulatory elements, especially within the $500 \mathrm{bp}$ proximal promoter region. The promoters of LHCB,Os_25, Os_26, Os_29, Os_34,Os_46, and Os_60 were also enriched in the NF-Y binding sites and may be co-regulated with $P s a O$ and $P s a K$ as part of the same NF-Y and NF-CO regulatory module. The promoter of $\mathrm{PsaO}$ was also enriched in cis-regulatory elements for bZIP, ERF, and MYB-related classes of TFs. The SGR promoter was characterized by several ABRE motifs and numerous consensus sequences for the NAP TF binding site (TACGT) and for MYB TFs, in particular, to those involved in dehydration and water stress response, like Arabidopsis MYB DOMAIN PROTEIN 2 (AtMYB2) (motifs MYB1AT and MYB2AT in Supplementary File S7) [61].

\section{Discussion}

Drought is a major environmental constraint for worldwide agriculture, and cereals are subjected to high yield loss due to this abiotic stress. As the world population is expected to reach nine billion people by 2050, crop yields need to be improved by $40 \%$ in areas where drought is likely to occur by 2025 [2,4]. The development of crops with increased drought tolerance can be achieved through advanced molecular breeding techniques or biotechnological approaches $[17,62]$. The prerequisite for the application of these strategies is the identification of drought-tolerant genes and the dissection of the biological mechanisms in which these genes are involved. Several efforts have been made in this direction, and one recent approach consists of meta-analyses of large transcriptomic datasets [34-37]. These analyses usually compare many experiments related to one species 
using data obtained with different cultivation methodologies, drought treatments, plant stages, analysed tissues, modalities, and timings of sampling, which often precludes the identification of useful targets for breeding programs. Instead, we selected four datasets related to four different cereal species that considered similar cultivation methodologies (i.e., plants grown in soil), drought treatments (i.e., severe stress for several days), plant stages (i.e., vegetative stage), and analysed tissues (i.e., leaf), to focus on specific drought tolerance mechanisms that are conserved among cereal species [29-32]. In addition, the selected transcriptomic studies were all performed on two contrasting genotypes since the comparison of genotypes showing contrasting responses to stress (tolerance and sensitivity) is crucial for identifying key players in the tolerant response $[27,28,33,63]$.

DEG analyses of the four datasets gave results comparable with the original ones [29-32]. The differences observed in the DEG numbers among the four species may be due to the different durations of the four drought treatments, since the amplitude of the activated transcriptome reflects the phases of the stress response [64]. Indeed, at the beginning of the stress treatment, sensitive genotypes are more conditioned by drought than tolerant ones and can undergo higher transcriptional fluctuations. After prolonged drought, the tolerant genotypes also sensed the stress with a consequent increase of gene expression fluctuations [64]. Consistently, the species subjected to a shorter treatment ( 8 and 7 days for Brachypodium and maize, respectively) showed fewer DEGs in tolerant genotypes, whereas in the barley experiment, where the stress experiment was more prolonged (30 days), the tolerant genotype showed a higher number of DEGs than the sensitive one. Nevertheless, one-to-one orthology analysis with the rice genome and the comparison with the drought treatments described by Todaka et al. [38] showed that the four experiments were comparable in terms of stress severity.

\subsection{CDT Genes Characterized the Drought Response of Sensitive and Tolerant Genotypes in the Four Cereal Species}

Based on the assumption that the expression of genes involved in the tolerant response to drought differs between sensitive and tolerant genotypes during the occurrence of the stress [35], we classified the DEGs putatively involved in drought tolerance in eight classes, according to their expression regulation under drought (Table 3). When the classified DEGs were compared among species, 69 genes that are possibly involved in the differentiation between drought-sensitive and tolerant responses and conserved among the four species were detected and called conserved drought tolerant-related (CDT) genes (Table S5). Thirty-six CDT genes were differentially expressed in the leaves of rice plants subjected to the Sds treatment reported in [38] (Table S3), confirming their relevant role in response to severe drought stress. PCA (Figure 2) and cluster analysis (Figure 4) of the CDT gene expression confirmed the ability of these genes to differentiate the tolerant from the sensitive genotypes in the four species by highlighting possible differences in the mechanisms of tolerance among the four species. Tolerant Brachypodium and maize genotypes displayed weak or no fluctuation of CDT gene expression in contrast to the dramatic changes in the sensitive genotypes, whereas, in barley and rice, both sensitive and tolerant genotypes displayed gene expression changes in response to the stress treatment.

Several CDT genes are known for their role in different biological processes, including photosynthesis, response to oxidative stress, chlorophyll biosynthesis and degradation, biosynthesis of secondary metabolites, hormone signalling, and cellular transport (more details are provided in Section 2.5). Several CDT genes involved in photosynthesis were strongly interconnected. In the principal PPI network (Figure 3), PsaO, PsaK, LHCB, the G3PDH Os04g0459500, and the SBP showed a high number of interactions, suggesting an important role within the network. The associations among $P s a O, P s a K$, and $L H C B$ were confirmed by the k-means cluster analysis of gene expression (Figure 4 and Supplementary File S4). These three genes, together with $C A 1$, which is involved in the $\mathrm{CO}_{2}$ fixation of photosynthesis, belonged to the same clusters in the four species (clusters 2, 3, 4, and 2 for Brachypodium, barley, maize, and rice, respectively), with the exception of PsaK in maize, which clustered independently in cluster 4 . This observation could be due to 
differences in the gene regulatory networks related to photosynthesis, since maize is a C4 species, while Brachypodium, barley. and rice are C3 [65]. These groups of genes were negatively correlated to $S G R$ homologous genes in the four species (i.e., belonging to the negatively correlated clusters). SGR is a major component of the chlorophyll degradation pathway and represents a key regulator of the leaf senescence process $[44,45]$. These data suggest the importance of photosynthesis and leaf senescence-related mechanisms in the differentiation between sensitive and tolerant responses to drought in cereals.

Among the CDT genes, 20 are not yet characterized (Table 5). Some of them are reported as chloroplastic proteins, and the putative orthologs of Arabidopsis are related to the assembly and functioning of photosystem II [66]. Most of these genes were positively correlated with the four photosynthetic genes $C A 1, P_{s a O}, P_{s a K}$, and $L H C B$, and negatively correlated with SGR (Supplementary Table S7), suggesting a role in photosynthesis. In addition, one of these uncharacterized genes, Os05g0468900, was previously detected among genes that are involved in the response to different abiotic stresses of contrasting rice genotypes [35], confirming an important role of this gene in the differentiation between sensitive and tolerant responses to environmental cues.

\subsection{The Balance between the Induction of Leaf Senescence and the Maintenance of Photosynthesis} Plays a Major Role in Drought Tolerance

Our findings point to a major role of the balance between SGR-mediated leaf senes-

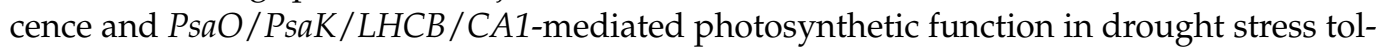
erance. Physiological leaf senescence is the final phase of the development of a leaf, where a self-destructive program to degenerate the cellular structures is activated and allows a leaf to make its final contribution to the plant by remobilizing the nutrients accumulated in the senescing leaf. During leaf senescence, several morphological, physiological, and molecular changes occur; photosynthesis is down-regulated, whereas nitrogen remobilization is up-regulated. The expressions of a high number of genes, called senescence-associated genes (SAGs), are modulated [67]. The four photosynthetic genes $P_{s a O}, P s a K, L H C B$ and $C A 1$ are reported as SAGs, as expected because of the down-regulation of photosynthetic activity [68]. Several other CDT genes were described as SAG [68] (Table S5). These genes are involved in the biological processes related to leaf senescence, such as chlorophyll biosynthesis, oxidative stress response, photosynthesis, JA-mediated signalling and cellular transport [69]. The regulation of leaf senescence has great importance in the life cycle of the plants and in terms of crop productivity since premature leaf senescence negatively impacts the yield stability, whereas delayed senescence and longer maintenance of photosynthesis can improve grain yield. Leaf senescence can be activated by abiotic stresses, including drought, through an ABA-mediated mechanism [70,71]. It has been demonstrated that the suppression of drought-induced leaf senescence in annual plants results in improved drought tolerance and minimal yield losses [72,73]. Hence, the balance between the induction of leaf senescence and the maintenance of photosynthesis can play a major role in drought tolerance and in preserving crop yields during stress.

\subsection{Identification of Transcription Factors Involved in the Balance between Leaf Senescence and Photosynthesis}

TFs are key players in the regulatory networks underlying plant responses to abiotic stresses [21,24]. Moreover, the importance of transcription regulation in the onset of leaf senescence is well-established [74]. TF-encoding genes were not found among the identified CDT genes, likely because for multigene families, such as TF families, the definition of orthologous relationships is a challenging task, and the commonly used predictive algorithms may fail the identification. However, the expressions of several TF genes were found as strictly associated with the specific CDT genes of the four species in the cluster analysis (Figure 4 and Supplementary File S4), suggesting that these specific TFs may regulate the expression of CDT genes. In addition, when low-stringency orthology analyses were carried out on the TF-encoding genes of the four species, we found that specific TF 
families were shared among two or three species (Table 5), suggesting a conserved role of these TFs among these cereal species.

To validate these findings, we used the transcriptomic data related to an independent experiment of osmotic stress on two contrasting rice genotypes [28] and constructed a GCN (Figure 5A). Topological parameters derived from the analysis of the GCN local properties are commonly used for node ranking to identify essential genes in the network, as well as co-expressed functional modules [75]. Thus, to identify TFs that could have a crucial role in the regulation of CDT genes, the rice TF genes associated with photosynthesis and SGR clusters were compared to the TF genes displaying both high node degrees in the GCN and high expression correlations with the selected CDT genes (Figure 5B, Supplementary File S5).

\subsection{Rice Transcription Factors Involved in the Positive Regulation of CDT Photosynthesis Genes}

Fourteen TF genes, which were strongly positively and negatively correlated to $\mathrm{PsaO}$ and $S G R$, respectively, were identified as putative regulators of the photosynthesis-related genes. In particular, genes belonging to the nuclear factor Y (NF-Y or NF-YB/NF-YC) and COSTANS-like (CO-like) groups attracted our attention. NF-Y is a heterotrimeric TF that binds CCAAT-box elements in eukaryotic promoters and is conserved from yeast to mammals [76]. NF-Y genes have been suggested to play a role in acclimatization strategies for abiotic stress tolerance [77]. In rice, the down-regulation of OsHAP3A (NF-YB) results in reduced chlorophyll content in the leaves, degenerate chloroplasts, and a marked reduction in the mRNA level of the light-harvesting chlorophyll a/b-binding protein gene [78]. CO-like proteins were shown to interact directly with several NF-YB/NF-YCs to impart DNA sequence specificity to the histone fold NF-YB/NF-YC dimer and efficiently regulate NF-CO target genes [79]. NF-Y and CO-like genes were present in the GCN group associated with photosynthetic genes, and some members of these classes had characteristics of hubs in the rice GCN, that is, the NF-YB Os03g0413000, the NF-YC Os03g0251350, and CO-like Os03g0711100. Cis-elements that can be directly bound by NF-Y and NF-CO complexes are present in several CDT photosynthetic genes, including $P s a O, P s a K$, and LHCB (Supplementary File S7). These NF-Y and CO-like TFs may therefore represent important TFs in the regulatory network underlying the promotion of photosynthesis vs. senescence in the establishment of drought stress tolerance.

Among the relevant TFs in the photosynthetic cluster and GCN, we found the bHLH TF OsPIL-13 (Os03g0782500) and the bZIP TF OsbZIP13 (Os02g0128200). OsPIL13 (also called OsPIL1) plays an important role in both leaf senescence [80] and drought tolerance [81]. Recently, OsPIL13 was found to promote chlorophyll biosynthesis [82]. Under drought, OsPIL13 acts as a key regulator of reduced internode elongation in rice under drought, and thus, may be important for morphological stress adaptation under drought conditions [81]. OsbZIP13 has been recognized as a major transcriptional regulator in the metabolic adjustments of rice under drought stress [83].

\subsection{Rice Transcription Factors Involved in the Positive Regulation of Leaf Senescence}

Twenty TF genes were strongly positively and negatively correlated to SGR and $P s a O$, respectively. These TFs can be positive regulators of leaf senescence. Among them, OsNAP, OsbZIP60 (Os07g0644100), and MCB2MYB (Os01g0863300) have been previously identified as candidate network hubs involved in the metabolic adjustments of rice under drought stress, as reported for OsbZIP13 [83]. This confirms the strong interconnection of the two identified pathways in drought response. OsNAP (Os03g0327800) is well known for its pivotal role in the induction of leaf senescence and in connecting abscisic acid and leaf senescence [84,85]. OsNAP has been also reported to be associated with JA biosynthesis [86].

Among the 20 putative regulators of leaf senescence, OsERF48 (Os08g0408500, also named OsDRAP1 or OsLG3), has been well characterized for its ability to confer drought tolerance in rice plants when overexpressed $[87,88]$. In addition, it is located in a QTL for drought tolerance [89], and a natural allele of this gene, which was isolated from a tolerant 
rice accession, is able to confer drought tolerance by inducing an enhanced ROS scavenging response [90].

The cis-element analysis (Supplementary File S7) showed that the SGR upstream sequence was enriched with putative binding sites for MYB, NAC, and ABRE TFs. This finding strengthened the hypothesis of direct regulation of the expression of $S G R$ and other genes by the described TFs. The positive regulation of OsNAP on SGR has been well documented $[84,85]$. However, the role of the other identified TFs is not known, and correlation data may not discriminate between the negative and positive activity of TFs. Indeed, ERF, bZIP, and MYB genes are able to both positively and negatively regulate downstream genes [21,91-93]. Hence, OsbZIP13 can act as a positive regulator of the photosynthesisrelated genes or a negative regulator of SGR. Similarly, OsbZIP60, MCB2MYB, and OsERF48 may induce SGR expression or repress the expression of photosynthesis-related genes. Further analyses are needed to reveal the exact role of these TFs.

3.6. Putative Orthologs of Rice Transcription Factors Are Involved in the Regulation of CDT Genes in Brachypodium, Barley, and Maize

We detected 18 candidate TF orthology groups potentially involved in the regulation of drought tolerance genes (Table 5). Interestingly, some rice TF genes, which we have described above as master regulators of gene expression regulation, were present in these orthology groups.

A bHLH group, which was related to photosynthesis, consisted of OsPIL13 and its putative orthologs, Bradi1g06670 and Zm00001d034298. Another photosynthesis-related group found in Brachypodium, rice, and maize consisted of OsbZIP13 and its putative orthologs Bradi3g02730, Zm00001d053967, and Zm00001d015118. The orthology analysis has also shown that the Bradi1g60030 is the putative ortholog of the NF-YB Os03g0413000, mentioned above as a possible master regulator of photosynthesis-related genes.

Regarding leaf senescence regulation, an orthology group consisted of OsERF48 and its putative orthologs Bradi3g35560 and Zm00001d032295. Moreover, an HD-ZIP orthology group (Bradi5g17170, HORVU2Hr1G092710, Zm00001d002799, and Zm00001d025964) was identified in Brachypodium, barley, and maize. The maize gene Zm00001d025964 was previously described as a candidate gene associated with leaf senescence [94]. The putative rice ortholog of these HD-ZIP genes is OsHOX22 (Os04g0541700), which is able to confer tolerance to drought and salt through an ABA-mediate mechanism when overexpressed [95]. $\mathrm{OsHOX} 22$ has been found to be differently regulated in sensitive and tolerant rice genotypes under both drought [96] and chilling [97] stresses. Conversely, a further study reported a similar up-regulation in both sensitive and tolerant cultivars under osmotic stress [98]. This data is consistent with the present analysis, where OsHOX22 resulted in up-regulated DEG with similar expression profiles between the two genotypes. This behaviour could be due to the presence of different alleles in the analysed rice genotypes. In sum, OsHOX22 was strongly negatively correlated to $P_{s a O}$ in the GCN (Table S7), confirming a role in the regulation of drought-related expression.

Finally, a bHLH orthology group, which is related to the SGR clusters, consisted of the three genes Bradi2g00730, HORVU3Hr1G000170, and Os01g0108400, which have not been characterized yet, and thus, may represent novel candidates for drought tolerance in these cereal crops.

In conclusion, our analysis revealed the importance of the balance between leaf senescence and the maintenance of photosynthesis in drought tolerance and suggested that the fine-tuning of this balance through gene expression modulation by specific TFs can be the key to improving the ability of cereal crops to tolerate drought stress. The proposed model is presented in Figure 6.

The accuracy in the dataset selection, the comparison between the tolerant and sensitive genotypes, the combination of gene expression information across species, and the in-house-developed bioinformatics pipeline allowed us to identify potential drought tolerance core genes with high evolutionary conservation in cereals. 
a)

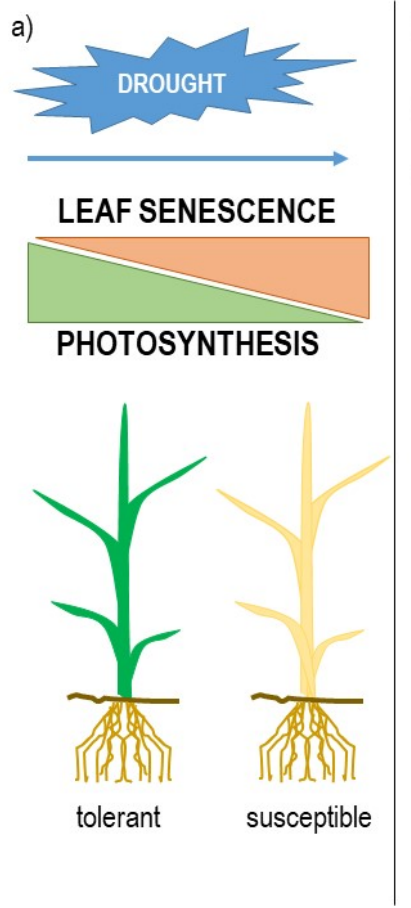

b)

b)
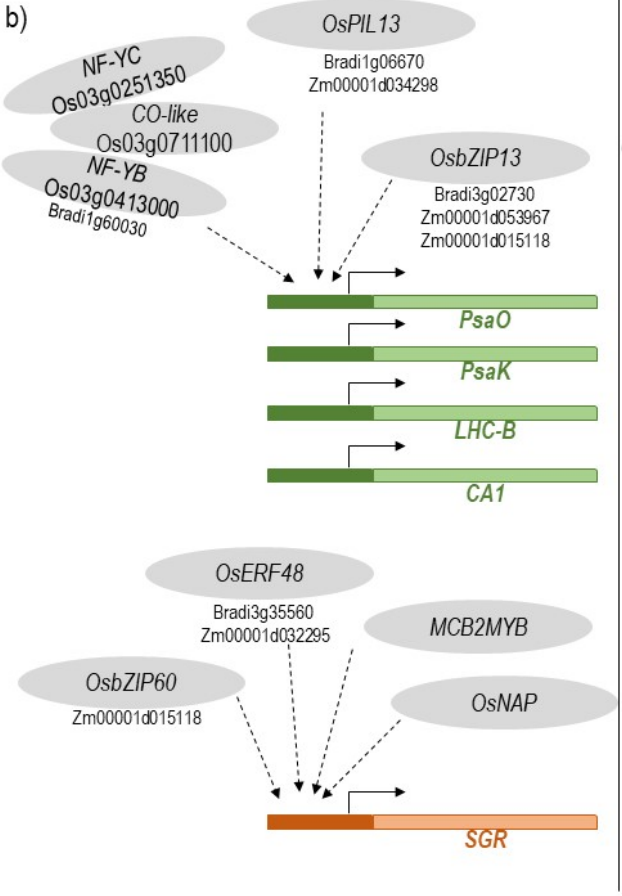

c)

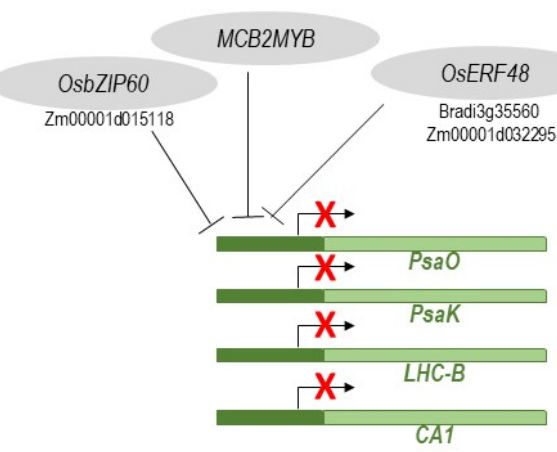

OsbZIP13

Bradi3902730

Zm000011053967

Zmo00010015118

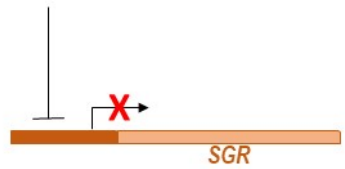

Figure 6. Proposed model for the differentiation of tolerant and sensitive response to drought stress in cereals. (a) The balance between induction of leaf senescence and maintenance of photosynthesis during drought is crucial for tolerance and is obtained through fine-tuning of gene expression by specific transcription factors (TFs). (b,c) The putative rice TFs involved in the regulation of genes related to photosynthesis (Psao, PsaK, LHCB, and CA1) and leaf senescence (SGR) are represented. Some of them may act as positive $(\mathbf{b})$ or negative (c) regulators. When identified, putative barley and maize orthologues of rice TF-encoding genes are indicated.

\section{Materials and Methods}

\subsection{Selection of Published RNA-Seq Studies}

Scientific papers about the transcriptomic analysis of tolerant response to drought in Gramineae species were searched in the Scopus and Google Scholar databases. The studies selected for this meta-analysis were selected based on the following criteria: (i) comparing the responses of two contrasting genotypes (one tolerant, one sensitive) to drought stress; (ii) drought stress performed in soil by withholding water for medium to long periods (several days, not hours) during the plant vegetative stage; (iii) RNA isolated from pooled samples of leaves; (iv) raw RNA-Seq data available in public repositories. These criteria resulted in the selection of 4 datasets belonging to 4 different species-B. distachyon [30], H. vulgare [29], O. sativa [32], and Z. mays [31]. If different time point series were carried out in the same study, a single time point was selected so that the drought severity was comparable with the other considered datasets. Table 1 summarizes the main features of the materials used for this study.

A defined code was used to standardize the sample identifiers. The first part of the name indicated the species ("Bd" $=B$. distachyon; " $\mathrm{Hv}^{\prime \prime}=H$. vulgare; "Os" = O. sativa; "Zm" = Z. mays), and the part following it was referred to as the drought stress-related phenotype of the cultivar ("sen" = sensitive; "tol" = tolerant). The last letter indicates the growth condition $(\mathrm{C}=$ control; $\mathrm{S}=$ stressed $)$, and the final number represents the biological replicate $(1,2$, or 3$)$.

\subsection{RNA-Seq Data Handling and Gene Expression Quantification}

The pipeline for RNA-Seq data handling was similar to the one that we used in a previous study [35]. Briefly, FastQC 0.11.9 [99] was used to assess the RNA read qualities 
of the libraries summarized in Table 1, while Trimmomatic 0.39 [100] was used to filter out the adaptor sequences and the low-quality bases. The filtered RNA reads were then mapped to the respective reference genome using HiSat2 2.2.1 aligner [101] with default parameters. The most recent reference genome assemblies for the species used in this study were retrieved from the EnsemblPlants website (http:/ / plants.ensembl.org/, accessed on 30 September 2021) on 7 February 2020. RNA reads of Brachypodium, barley, maize, and rice were mapped to the B. distachyon v3.0 [102], H. vulgare IBSC v2 [103], Z. mays B73 RefGen v4 [104], and O. sativa ssp. japonica IRGSP-1.0 [105] genome assemblies, respectively.

Finally, read counts were generated from alignment files with featureCounts software, part of the Subread package 1.6.2 [106], with default parameters, basing on 'exon' feature into 'gene_id' meta-feature of gtf annotation files retrieved from the EnsemblPlants website (http:/ / plants.ensembl.org/, accessed on 30 September 2021) on 7 February 2020. The annotation files used for the reads counts were B. distachyon v3.0.46, H. vulgare IBSC v2.46, Z. mays B73 RefGen v4.46, and O. sativa IRGSP 1.0.46. Multi-mapping and multi-overlapping reads were not counted.

\subsection{Differential Expression Analysis and Orthology Study}

DE analyses comparing the stressed and control samples were carried out separately for each dataset using Bioconductor EdgeR 3.28.1 [107] in the R environment. EdgeR was used to (i) filter out the genes that were not expressed or poorly expressed (a gene was considered "active" if the reads per million mapped to that gene were $>1$ in at least two libraries), (ii) normalize the RNA libraries, and (iii) perform the differential expression analysis with the likelihood ratio test comparing the treated (stressed) samples to the control (not stressed) ones. The $\log _{2}$ fold change (LFC) of expression between the treated and control samples was calculated with EdgeR, whose computing approach fits a negative binomial generalized linear model (GLM) to the read counts for each gene. The genes with a resulting false discovery rate (FDR) smaller than 0.05 were considered DEGs. No LFC cut-off was used for DEG identification.

In order to identify the orthologous rice genes for the other three species, a complete list of orthologous genes corresponding to O. sativa from Ensembl plants was collected. An in-house Perl script was run to parse the corresponding ortholog gene from B. distachyon, Z. mais, and H. vulgare.

\subsection{Transcription Factors Annotation and Orthology}

Manually-curated TF annotations for the four cereal species were carried out on the DEG genes for each species, combining TF annotations already present in the plant transcription factor database (Plant TFDB 3.0; [108]), the gene description from the reference genome assemblies (B. distachyon v3.0.46, H. vulgare IBSC v2.46, Z. mays B73 RefGen v4.46, and $O$. sativa IRGSP 1.0.46), and the best $A$. thaliana orthology hits. TF classes were annotated according to the plant TFDB classification. For the orthology analysis, the gene IDs of the $B$. distachyon, $H$. vulgare, and Z. mays TFs in the negatively correlated clusters related to photosynthesis and senescence were used for searching the corresponding orthologues (to a maximum of 6) in rice using the Ensembl Biomart tool in the plant platform [109]. The resulting rice IDs were used in a VENN analysis to identify those that were common to more species.

\subsection{Protein-Protein Interaction Network Analysis}

Protein-protein interaction (PPI) networks were analysed with STRING v11 [110], using a combined score threshold of 0.7 .

\subsection{K-Means Cluster Analysis}

The pipeline for the k-means cluster analysis was performed according to Testone et al. (2019) with some modifications. Briefly, normalized counts from EdgeR were converted to transcripts per kilobase million (TPM) for each species with the following procedure: the read 
counts were divided by the length of each gene in kilobases to obtain reads per kilobase (RPK); all the RPK values in a sample were counted and this number was divided by $1,000,000$ to obtain the "per million" scaling factor; the RPK values were divided by the "per million" scaling factor to obtain the TPM values. TPM means values of TF DEGs and of the 69 CDT genes were used for cluster analysis. The TPM means from each sample were $\log$-transformed using $\log _{2}(x+1)$ for data normalization. Each gene was indexed according to the species (Bd: B. distachyon; Hv: H. vulgare; Os: O. sativa; Zm: Z. mays). The optimum number of clusters was determined as described by Testone et al. (2019) [58]. Data scaling, k-means clustering, and visualization were performed in $\mathrm{R}$ according to the methods of Morgan et al. [111].

\subsection{Gene Co-Expression Network (GCN) Construction and Analysis}

For the GCN construction, we used the RPKM gene expression values of CDTs and differentially expressed TF genes from a previous experiment of PEG-mediated osmotic stress in rice [28]. The data were $\log$-transformed using $\log _{2}(x+1)$ for normalization, and Pearson pairwise correlation analysis was conducted across the selected samples using the "corrplot" and "hclust" R packages of R software [112]. Significant correlations ( $p$-value $\leq 0.05)$, with a Pearson's correlation coefficient $(r) \geq|0.9|$ were used for the construction of co-expression networks and network analysis in the Cytoscape software platform v. 3.5.1 [59].

\subsection{Analysis of the Cis-Regulatory Elements in the CDT Promoters}

Cis-regulatory motif analysis was carried out using the regulatory sequence analysis tools (RSAT) web platform [113]. The $3000 \mathrm{bp}$ regions upstream of the translation start sites of the 69 CDT rice genes were retrieved from the O. sativa Japonica IRGSP-1 genome using the RSAT retrieve sequence tool. The sequences were then analysed for the presence of 16 consensus motifs for NF-Y, NF-CO, NAC, bZIP, MYB, and ERF TFs $[79,114,115]$ (Supplementary File S7). The total/average values in the $3000 \mathrm{bp}$ of each motif were calculated by dividing the total number of motifs found in the $3000 \mathrm{bp}$ promoters of all rice annotated genes by the number of rice annotated genes. This value was then used to identify CDT genes enriched in a particular motif by dividing the number of motif hits by the average motif occurrence in the $3000 \mathrm{bp}$ regulatory regions of rice genes.

Supplementary Materials: The following are available online at https:/ / www.mdpi.com/article/10 .3390/ijms222313062/s1.

Author Contributions: M.B. and E.B. conceived and designed the research; M.B. analysed the transcriptome data and performed the RNA-Seq data processing and differential expression analyses; G.F. performed the PCA, k-means clustering, gene co-expression network, binding site recognition, and transcription factor orthology; J.B. performed the rice gene orthology analysis; F.M. performed the PPI analysis; E.B. and D.P. gathered the literature; E.B. and G.F. performed the data interpretation; E.B., M.B. and G.F. wrote the manuscript. All authors have read and agreed to the published version of the manuscript.

Funding: This work was partially supported by the projects "Economia Circolare (Green and Circular Economy-GECE)", FOE 2019 (MIUR), Decreto Ministeriale n. 856 del 10/10/2019, and “Gruppi di Ricerca 2020" SMART-BREED Project A0375E0166, POR FESR LAZIO 2014-2020.

Informed Consent Statement: Informed consent was obtained from all individual participants included in the study.

Conflicts of Interest: On behalf of all authors, the corresponding author states that there is no conflict of interest. This article does not contain any studies with human participants performed by any of the authors.

\section{References}

1. Lesk, C.; Rowhani, P.; Ramankutty, N. Influence of extreme weather disasters on global crop production. Nature 2016, 529, 84-87. [CrossRef] [PubMed] 
2. Daryanto, S.; Wang, L.; Jacinthe, P.A. Global synthesis of drought effects on maize and wheat production. PLoS ONE 2016, 11, e0156362. [CrossRef]

3. Tardieu, F.; Simonneau, T.; Muller, B. The Physiological Basis of Drought Tolerance in Crop Plants: A Scenario-Dependent Probabilistic Approach. Annu. Rev. Plant Biol. 2018, 69, 733-759. [CrossRef]

4. Bailey-Serres, J.; Parker, J.E.; Ainsworth, E.A.; Oldroyd, G.E.D.; Schroeder, J.I. Genetic strategies for improving crop yields. Nature 2019, 575, 109-118. [CrossRef]

5. Trenberth, K.E.; Dai, A.; Van Der Schrier, G.; Jones, P.D.; Barichivich, J.; Briffa, K.R.; Sheffield, J. Global warming and changes in drought. Nat. Clim. Chang. 2014, 4, 17-22. [CrossRef]

6. Fàbregas, N.; Fernie, A.R. The metabolic response to drought. J. Exp. Bot. 2019, 70, 1077-1085. [CrossRef] [PubMed]

7. Blum, A. Osmotic adjustment is a prime drought stress adaptive engine in support of plant production. Plant Cell Environ. 2017, 40, 4-10. [CrossRef]

8. Per, T.S.; Khan, N.A.; Reddy, P.S.; Masood, A.; Hasanuzzaman, M.; Khan, M.I.R.; Anjum, N.A. Approaches in modulating proline metabolism in plants for salt and drought stress tolerance: Phytohormones, mineral nutrients and transgenics. Plant Physiol. Biochem. 2017, 115, 126-140. [CrossRef]

9. Claeys, H.; Inzé, D. The agony of choice: How plants balance growth and survival under water-limiting conditions. Plant Physiol. 2013, 162, 1768-1779. [CrossRef]

10. Estravis-Barcala, M.; Mattera, M.G.; Soliani, C.; Bellora, N.; Opgenoorth, L.; Heer, K.; Arana, M.V.; Gutiérrez, R. Molecular bases of responses to abiotic stress in trees. J. Exp. Bot. 2020, 71, 3765-3779. [CrossRef] [PubMed]

11. Laxa, M.; Liebthal, M.; Telman, W.; Chibani, K.; Dietz, K.J. The role of the plant antioxidant system in drought tolerance. Antioxidants 2019, 8, 94. [CrossRef] [PubMed]

12. Peleg, Z.; Blumwald, E. Hormone balance and abiotic stress tolerance in crop plants. Curr. Opin. Plant Biol. 2011, 14, 290-295. [CrossRef] [PubMed]

13. Kazan, K. Diverse roles of jasmonates and ethylene in abiotic stress tolerance. Trends Plant Sci. 2015, 20, 219-229. [CrossRef]

14. de Ollas, C.; Dodd, I.C. Physiological impacts of ABA-JA interactions under water-limitation. Plant Mol. Biol. 2016, 91, 641-650. [CrossRef] [PubMed]

15. Shinozaki, K.; Yamaguchi-Shinozaki, K. Gene networks involved in drought stress response and tolerance. J. Exp. Bot. 2007, 58, 221-227. [CrossRef] [PubMed]

16. Yoshida, T.; Mogami, J.; Yamaguchi-Shinozaki, K. ABA-dependent and ABA-independent signaling in response to osmotic stress in plants. Curr. Opin. Plant Biol. 2014, 21, 133-139. [CrossRef] [PubMed]

17. Todaka, D.; Shinozaki, K.; Yamaguchi-Shinozaki, K. Recent advances in the dissection of drought-stress regulatory networks and strategies for development of drought-tolerant transgenic rice plants. Front. Plant Sci. 2015, 6, 84. [CrossRef]

18. Nakashima, K.; Takasaki, H.; Mizoi, J.; Shinozaki, K.; Yamaguchi-Shinozaki, K. NAC transcription factors in plant abiotic stress responses. Biochim. Biophys. Acta-Gene Regul. Mech. 2012, 1819, 97-103. [CrossRef] [PubMed]

19. Dietz, K.J.; Vogel, M.O.; Viehhauser, A. AP2/EREBP transcription factors are part of gene regulatory networks and integrate metabolic, hormonal and environmental signals in stress acclimation and retrograde signalling. Protoplasma 2010, $245,3-14$. [CrossRef]

20. Sun, X.; Wang, Y.; Sui, N. Transcriptional regulation of bHLH during plant response to stress. Biochem. Biophys. Res. Commun. 2018, 503, 397-401. [CrossRef]

21. Baldoni, E.; Genga, A.; Cominelli, E. Plant MYB transcription factors: Their role in drought response mechanisms. Int. J. Mol. Sci. 2015, 16, 15811-15851. [CrossRef]

22. Li, W.; Pang, S.; Lu, Z.; Jin, B. Function and mechanism of WRKY transcription factors in abiotic stress responses of plants. Plants 2020, 9, 1515. [CrossRef]

23. Han, G.; Lu, C.; Guo, J.; Qiao, Z.; Sui, N.; Qiu, N.; Wang, B. C2H2 Zinc Finger Proteins: Master Regulators of Abiotic Stress Responses in Plants. Front. Plant Sci. 2020, 11, 115. [CrossRef] [PubMed]

24. Golldack, D.; Li, C.; Mohan, H.; Probst, N. Tolerance to drought and salt stress in plants: Unraveling the signaling networks. Front. Plant Sci. 2014, 5, 151. [CrossRef]

25. Chandra, B.R. Breeding for drought resistance in rice: An integrated view from physiology. Babu R. Chandra 2010, 1, 1133-1141.

26. Fukai, S.; Cooper, M. Development of drought-resistant cultivars using physiomorphological traits in rice. Field Crops Res. 1995, 40, 67-86. [CrossRef]

27. Zhang, Z.F.; Li, Y.Y.; Xiao, B.Z. Comparative transcriptome analysis highlights the crucial roles of photosynthetic system in drought stress adaptation in upland rice. Sci. Rep. 2016, 6, 1-13. [CrossRef]

28. Baldoni, E.; Bagnaresi, P.; Locatelli, F.; Mattana, M.; Genga, A. Comparative Leaf and Root Transcriptomic Analysis of two Rice Japonica Cultivars Reveals Major Differences in the Root Early Response to Osmotic Stress. Rice 2016, 9, 1-20. [CrossRef]

29. Cantalapiedra, C.P.; García-Pereira, M.J.; Gracia, M.P.; Igartua, E.; Casas, A.M.; Contreras-Moreira, B. Large differences in gene expression responses to drought and heat stress between elite barley cultivar scarlett and a Spanish landrace. Front. Plant Sci. 2017, 8, 647. [CrossRef] [PubMed]

30. Lenk, I.; Fisher, L.H.C.; Vickers, M.; Akinyemi, A.; Didion, T.; Swain, M.; Jensen, C.S.; Mur, L.A.J.; Bosch, M. Transcriptional and metabolomic analyses indicate that cell wall properties are associated with drought tolerance in brachypodium distachyon. Int. J. Mol. Sci. 2019, 20, 1758. [CrossRef] 
31. Zenda, T.; Liu, S.; Wang, X.; Liu, G.; Jin, H.; Dong, A.; Yang, Y.; Duan, H. Key maize drought-responsive genes and pathways revealed by comparative transcriptome and physiological analyses of contrasting inbred lines. Int. J. Mol. Sci. 2019, 20, 1268. [CrossRef]

32. Wei, H.; Lou, Q.; Xu, K.; Yan, M.; Xia, H.; Ma, X.; Yu, X.; Luo, L. Alternative splicing complexity contributes to genetic improvement of drought resistance in the rice maintainer HuHan2B. Sci. Rep. 2017, 7, 1-13. [CrossRef]

33. Lenka, S.K.; Katiyar, A.; Chinnusamy, V.; Bansal, K.C. Comparative analysis of drought-responsive transcriptome in Indica rice genotypes with contrasting drought tolerance. Plant Biotechnol. J. 2011, 9, 315-327. [CrossRef]

34. Muthuramalingam, P.; Krishnan, S.R.; Pothiraj, R.; Ramesh, M. Global transcriptome analysis of combined abiotic stress signaling genes unravels key players in Oryza sativa L.: An in silico approach. Front. Plant Sci. 2017, 8, 759. [CrossRef]

35. Buti, M.; Baldoni, E.; Formentin, E.; Milc, J.; Frugis, G.; Lo Schiavo, F.; Genga, A.; Francia, E. A meta-analysis of comparative transcriptomic data reveals a set of key genes involved in the tolerance to abiotic stresses in rice. Int. J. Mol. Sci. 2019, $20,5662$. [CrossRef] [PubMed]

36. Sircar, S.; Parekh, N. Meta-analysis of drought-tolerant genotypes in Oryza sativa: A network-based approach. PLoS ONE 2019, 14, e0216068. [CrossRef]

37. Cohen, S.P.; Leach, J.E. Abiotic and biotic stresses induce a core transcriptome response in rice. Sci. Rep. 2019, 9, 1-11. [CrossRef]

38. Todaka, D.; Zhao, Y.; Yoshida, T.; Kudo, M.; Kidokoro, S.; Mizoi, J.; Kodaira, K.S.; Takebayashi, Y.; Kojima, M.; Sakakibara, H.; et al. Temporal and spatial changes in gene expression, metabolite accumulation and phytohormone content in rice seedlings grown under drought stress conditions. Plant J. 2017, 90, 61-78. [CrossRef] [PubMed]

39. Yamaguchi-Shinozaki, K.; Shinozaki, K. The plant hormone abscisic acid mediates the drought-induced expression but not the seed-specific expression of rd22, a gene responsive to dehydration stress in Arabidopsis thaliana. MGG Mol. Gen. Genet. 1993, 238, 17-25. [CrossRef] [PubMed]

40. Martínez, I.M.; Chrispeels, M.J. Genomic analysis of the unfolded protein response in Arabidopsis shows its connection to important cellular processes. Plant Cell 2003, 15, 561-576. [CrossRef]

41. Jensen, P.E.; Bassi, R.; Boekema, E.J.; Dekker, J.P.; Jansson, S.; Leister, D.; Robinson, C.; Scheller, H.V. Structure, function and regulation of plant photosystem I. Biochim. Biophys. Acta-Bioenerg. 2007, 1767, 335-352. [CrossRef] [PubMed]

42. Chen, T.; Wu, H.; Wu, J.; Fan, X.; Li, X.; Lin, Y. Absence of Os $\beta C A 1$ causes a CO2 deficit and affects leaf photosynthesis and the stomatal response to $\mathrm{CO}_{2}$ in rice. Plant J. 2017, 90, 344-357. [CrossRef]

43. Muthusamy, S.K.; Lenka, S.K.; Katiyar, A.; Chinnusamy, V.; Singh, A.K.; Bansal, K.C. Genome-Wide Identification and Analysis of Biotic and Abiotic Stress Regulation of C 4 Photosynthetic Pathway Genes in Rice. Appl. Biochem. Biotechnol. 2019, 187, $221-238$. [CrossRef]

44. Jiang, H.; Li, M.; Liang, N.; Yan, H.; Wei, Y.; Xu, X.; Liu, J.; Xu, Z.; Chen, F.; Wu, G. Molecular cloning and function analysis of the stay green gene in rice. Plant J. 2007, 52, 197-209. [CrossRef] [PubMed]

45. Park, S.Y.; Yu, J.W.; Park, J.S.; Li, J.; Yoo, S.C.; Lee, N.Y.; Lee, S.K.; Jeong, S.W.; Hak, S.S.; Koh, H.J.; et al. The senescence-induced staygreen protein regulates chlorophyll degradation. Plant Cell 2007, 19, 1649-1664. [CrossRef]

46. Rong, H.; Tang, Y.; Zhang, H.; Wu, P.; Chen, Y.; Li, M.; Wu, G.; Jiang, H. The Stay-Green Rice like (SGRL) gene regulates chlorophyll degradation in rice. J. Plant Physiol. 2013, 170, 1367-1373. [CrossRef]

47. Zeng, Z.; Lin, T.; Zhao, J.; Zheng, T.; Xu, L.; Wang, Y.; Liu, L.; Jiang, L.; Chen, S.; Wan, J. OsHemA gene, encoding glutamyl-tRNA reductase (GluTR) is essential for chlorophyll biosynthesis in rice (Oryza sativa). J. Integr. Agric. 2020, 19, 612-623. [CrossRef]

48. Zhou, Q.; Yu, Q.; Wang, Z.; Pan, Y.; Lv, W.; Zhu, L.; Chen, R.; He, G. Knockdown of GDCH gene reveals reactive oxygen species-induced leaf senescence in rice. Plant Cell Environ. 2013, 36, 1476-1489. [CrossRef]

49. Kolton, M.; Keren, I.; Shevtsov, S.; Shaya, F.; Peled-Zehavi, H.; Danon, A.; Ostersetzer-Biran, O. Plastidic redox switches: Ferredoxins as novel RNA-binding proteins. J. Endocytobiosis Cell Res. 2011, 5, 1-18.

50. Mei, J.; Li, F.; Liu, X.; Hu, G.; Fu, Y.; Liu, W. Newly identified CSP41b gene localized in chloroplasts affects leaf color in rice. Plant Sci. 2017, 256, 39-45. [CrossRef]

51. Wang, G.F.; Li, W.Q.; Li, W.Y.; Wu, G.L.; Zhou, C.Y.; Chen, K.M. Characterization of rice NADPH oxidase genes and their expression under various environmental conditions. Int. J. Mol. Sci. 2013, 14, 9440-9458. [CrossRef]

52. Fang, C.; Li, L.; Zhang, P.; Wang, D.; Yang, L.; Reza, B.M.; Lin, W. Lsi1 modulates the antioxidant capacity of rice and protects against ultraviolet-B radiation. Plant Sci. 2019, 278, 96-106. [CrossRef]

53. Bai, Z.; Qi, T.; Liu, Y.; Wu, Z.; Ma, L.; Liu, W.; Cao, Y.; Bao, Y.; Fu, C. Alteration of S-adenosylhomocysteine levels affects lignin biosynthesis in switchgrass. Plant Biotechnol. J. 2018, 16, 2016-2026. [CrossRef]

54. Chen, X.; Tao, Y.; Ali, A.; Zhuang, Z.; Guo, D.; Guo, Q.; Riaz, A.; Zhang, H.; Xu, P.; Liao, Y.; et al. Transcriptome and Proteome Profiling of Different Colored Rice Reveals Physiological Dynamics Involved in the Flavonoid Pathway. Int. J. Mol. Sci. 2019, $20,2463$. [CrossRef]

55. Lee, A.; Cho, K.; Jang, S.; Rakwal, R.; Iwahashi, H.; Agrawal, G.K.; Shim, J.; Han, O. Inverse correlation between jasmonic acid and salicylic acid during early wound response in rice. Biochem. Biophys. Res. Commun. 2004, 318, 734-738. [CrossRef] [PubMed]

56. Shim, Y.; Kang, K.; An, G.; Paek, N.C. Rice DNA-Binding One Zinc Finger 24 (OsDOF24) Delays Leaf Senescence in a JasmonateMediated Pathway. Plant Cell Physiol. 2019, 60, 2065-2076. [CrossRef] [PubMed]

57. He, Y.; Zhao, J.; Yang, B.; Sun, S.; Peng, L.; Wang, Z. Indole-3-acetate beta-glucosyltransferase OsIAGLU regulates seed vigour through mediating crosstalk between auxin and abscisic acid in rice. Plant Biotechnol. J. 2020, 18, 1933-1945. [CrossRef] [PubMed] 
58. Testone, G.; Baldoni, E.; Iannelli, M.A.; Nicolodi, C.; Di Giacomo, E.; Pietrini, F.; Mele, G.; Giannino, D.; Frugis, G. Transcription factor networks in leaves of cichorium endivia: New insights into the relationship between photosynthesis and leaf development. Plants 2019, 8, 531. [CrossRef]

59. Shannon, P.; Markiel, A.; Ozier, O.; Baliga, N.S.; Wang, J.T.; Ramage, D.; Amin, N.; Schwikowski, B.; Ideker, T. Cytoscape: A software environment for integrated models of biomolecular interaction networks. Genome Res. 2003, 13, 2498-2504. [CrossRef]

60. Hu, J.X.; Thomas, C.E.; Brunak, S. Network biology concepts in complex disease comorbidities. Nat. Rev. Genet. 2016, 17, 615-629. [CrossRef]

61. Urao, T.; Yamaguchi-Shinozaki, K.; Urao, S.; Shinozaki, K. An Arabidopsis myb homolog is induced by dehydration stress and its gene product binds to the conserved MYB recognition sequence. Plant Cell 1993, 5, 1529-1539. [CrossRef] [PubMed]

62. Hu, H.; Xiong, L. Genetic engineering and breeding of drought-resistant crops. Annu. Rev. Plant Biol. 2014, 65, 715-741. [CrossRef] [PubMed]

63. Buti, M.; Pasquariello, M.; Ronga, D.; Milc, J.A.; Pecchioni, N.; Ho, V.T.; Pucciariello, C.; Perata, P.; Francia, E. Transcriptome profiling of short-term response to chilling stress in tolerant and sensitive Oryza sativa ssp. Japonica seedlings. Funct. Integr. Genom. 2018, 18, 627-644. [CrossRef] [PubMed]

64. Bjornson, M.; Dandekar, A.; Dehesh, K. Determinants of timing and amplitude in the plant general stress response. J. Integr. Plant Biol. 2016, 58, 119-126. [CrossRef]

65. Tahmasebi, A.; Niazi, A. Comparison of Transcriptional Response of C3 and C4 Plants to Drought Stress Using Meta-Analysis and Systems Biology Approach. Front. Plant Sci. 2021, 12, 668736. [CrossRef] [PubMed]

66. Dal Bosco, C.; Lezhneva, L.; Bieh, A.; Leister, D.; Strotmann, H.; Wanner, G.; Meurer, J. Inactivation of the Chloroplast ATP Synthase $\gamma$ Subunit Results in High Non-photochemical Fluorescence Quenching and Altered Nuclear Gene Expression in Arabidopsis thaliana. J. Biol. Chem. 2004, 279, 1060-1069. [CrossRef]

67. Wu, X.Y.; Kuai, B.K.; Jia, J.Z.; Jing, H.C. Regulation of Leaf Senescence and Crop Genetic Improvement. J. Integr. Plant Biol. 2012, 54, 936-952. [CrossRef]

68. Lee, S.; Jeong, H.; Lee, S.; Lee, J.; Kim, S.J.; Park, J.W.; Woo, H.R.; Lim, P.O.; An, G.; Nam, H.G.; et al. Molecular bases for differential aging programs between flag and second leaves during grain-filling in rice. Sci. Rep. 2017, 7, 1-16. [CrossRef]

69. Leng, Y.; Ye, G.; Zeng, D. Genetic dissection of leaf senescence in rice. Int. J. Mol. Sci. 2017, 18, 2686. [CrossRef]

70. Mao, C.; Lu, S.; Lv, B.; Zhang, B.; Shen, J.; He, J.; Luo, L.; Xi, D.; Chen, X.; Ming, F. A rice nac transcription factor promotes leaf senescence via ABA biosynthesis. Plant Physiol. 2017, 174, 1747-1763. [CrossRef]

71. Takasaki, H.; Maruyama, K.; Takahashi, F.; Fujita, M.; Yoshida, T.; Nakashima, K.; Myouga, F.; Toyooka, K.; Yamaguchi-Shinozaki, K.; Shinozaki, K. SNAC-As, stress-responsive NAC transcription factors, mediate ABA-inducible leaf senescence. Plant J. 2015, 84, 1114-1123. [CrossRef]

72. Rivero, R.M.; Kojima, M.; Gepstein, A.; Sakakibara, H.; Mittler, R.; Gepstein, S.; Blumwald, E. Delayed leaf senescence induces extreme drought tolerance in a flowering plant. Proc. Natl. Acad. Sci. USA 2007, 104, 19631-19636. [CrossRef] [PubMed]

73. Kamal, N.M.; Gorafi, Y.S.A.; Abdelrahman, M.; Abdellatef, E.; Tsujimoto, H. Stay-green trait: A prospective approach for yield potential, and drought and heat stress adaptation in globally important cereals. Int. J. Mol. Sci. 2019, 20, 5837. [CrossRef] [PubMed]

74. Jan, S.; Abbas, N.; Ashraf, M.; Ahmad, P. Roles of potential plant hormones and transcription factors in controlling leaf senescence and drought tolerance. Protoplasma 2019, 256, 313-329. [CrossRef] [PubMed]

75. Serin, E.A.R.; Nijveen, H.; Hilhorst, H.W.M.; Ligterink, W. Learning from Co-expression Networks: Possibilities and Challenges. Front. Plant Sci. 2016, 7, 444. [CrossRef]

76. Zanetti, M.E.; Rípodas, C.; Niebel, A. Plant NF-Y transcription factors: Key players in plant-microbe interactions, root development and adaptation to stress. Biochim. Biophys. Acta-Gene Regul. Mech. 2017, 1860, 645-654. [CrossRef] [PubMed]

77. Leyva-González, M.A.; Ibarra-Laclette, E.; Cruz-Ramírez, A.; Herrera-Estrella, L. Functional and Transcriptome Analysis Reveals an Acclimatization Strategy for Abiotic Stress Tolerance Mediated by Arabidopsis NF-YA Family Members. PLoS ONE 2012, 7, e0048138. [CrossRef]

78. Miyoshi, K.; Ito, Y.; Serizawa, A.; Kurata, N. OsHAP3 genes regulate chloroplast biogenesis in rice. Plant J. 2003, 36, 532-540. [CrossRef] [PubMed]

79. Gnesutta, N.; Kumimoto, R.W.; Swain, S.; Chiara, M.; Siriwardana, C.; Horner, D.S.; Holt, B.F.; Mantovani, R. CONSTANS imparts DNA sequence specificity to the histone fold NF-YB/NF-YC Dimer. Plant Cell 2017, 29, 1516-1532. [CrossRef] [PubMed]

80. Piao, W.; Kim, E.Y.; Han, S.H.; Sakuraba, Y.; Paek, N.C. Rice phytochrome B (OsPhyB) negatively regulates dark- and starvationinduced leaf senescence. Plants 2015, 4, 644-663. [CrossRef]

81. Todaka, D.; Nakashima, K.; Maruyama, K.; Kidokoro, S.; Osakabe, Y.; Ito, Y.; Matsukura, S.; Fujita, Y.; Yoshiwara, K.; Ohme-Takagi, M.; et al. Rice phytochrome-interacting factor-like protein OsPIL1 functions as a key regulator of internode elongation and induces a morphological response to drought stress. Proc. Natl. Acad. Sci. USA 2012, 109, 15947-15952. [CrossRef]

82. Sakuraba, Y.; Kim, E.Y.; Han, S.H.; Piao, W.; An, G.; Todaka, D.; Yamaguchi-Shinozaki, K.; Paek, N.C. Rice PhytochromeInteracting Factor-Like1 (OsPIL1) is involved in the promotion of chlorophyll biosynthesis through feed-forward regulatory loops. J. Exp. Bot. 2017, 68, 4103-4114. [CrossRef] [PubMed] 
83. Mohanty, B.; Kitazumi, A.; Cheung, C.Y.M.; Lakshmanan, M.; de los Reyes, B.G.; Jang, I.C.; Lee, D.Y. Identification of candidate network hubs involved in metabolic adjustments of rice under drought stress by integrating transcriptome data and genome-scale metabolic network. Plant Sci. 2016, 242, 224-239. [CrossRef]

84. Chen, X.; Wang, Y.; Lv, B.; Li, J.; Luo, L.; Lu, S.; Zhang, X.; Ma, H.; Ming, F. The NAC family transcription factor OsNAP confers abiotic stress response through the ABA pathway. Plant Cell Physiol. 2014, 55, 604-619. [CrossRef]

85. Liang, C.; Wang, Y.; Zhu, Y.; Tang, J.; Hu, B.; Liu, L.; Ou, S.; Wu, H.; Sun, X.; Chu, J.; et al. OsNAP connects abscisic acid and leaf senescence by fine-tuning abscisic acid biosynthesis and directly targeting senescence-associated genes in rice. Proc. Natl. Acad. Sci. USA 2014, 111, 10013-10018. [CrossRef]

86. Zhou, Y.; Huang, W.; Liu, L.; Chen, T.; Zhou, F.; Lin, Y. Identification and functional characterization of a rice NAC gene involved in the regulation of leaf senescence. BMC Plant Biol. 2013, 13, 1-13. [CrossRef]

87. Jung, H.; Chung, P.J.; Park, S.H.; Redillas, M.C.F.R.; Kim, Y.S.; Suh, J.W.; Kim, J.K. Overexpression of OsERF48 causes regulation of OsCML16, a calmodulin-like protein gene that enhances root growth and drought tolerance. Plant Biotechnol. J. 2017, 15, 1295-1308. [CrossRef]

88. Chen, M.; Chen, J.; Luo, N.; Qu, R.; Guo, Z.; Lu, S. Cholesterol accumulation by suppression of SMT1 leads to dwarfism and improved drought tolerance in herbaceous plants. Plant Cell Environ. 2018, 41, 1417-1426. [CrossRef] [PubMed]

89. Baisakh, N.; Yabes, J.; Gutierrez, A.; Mangu, V.; Ma, P.; Famoso, A.; Pereira, A. Genetic mapping identifies consistent quantitative trait loci for yield traits of rice under greenhouse drought conditions. Genes 2020, 11, 62. [CrossRef] [PubMed]

90. Xiong, H.; Yu, J.; Miao, J.; Li, J.; Zhang, H.; Wang, X.; Liu, P.; Zhao, Y.; Jiang, C.; Yin, Z.; et al. Natural variation in OsLG3 increases drought tolerance in rice by inducing ROS scavenging. Plant Physiol. 2018, 178, 451-467. [CrossRef]

91. Baldoni, E.; Genga, A.; Medici, A.; Coraggio, I.; Locatelli, F. The OsMyb4 gene family: Stress response and transcriptional auto-regulation mechanisms. Biol. Plant. 2013, 57, 691-700. [CrossRef]

92. Mizoi, J.; Shinozaki, K.; Yamaguchi-Shinozaki, K. AP2/ERF family transcription factors in plant abiotic stress responses. Biochim. Biophys. Acta-Gene Regul. Mech. 2012, 1819, 86-96. [CrossRef]

93. Zhang, M.; Liu, Y.; Cai, H.; Guo, M.; Chai, M.; She, Z.; Ye, L.; Cheng, Y.; Wang, B.; Qin, Y. The bzip transcription factor gmbzip15 negatively regulates salt-and drought-stress responses in soybean. Int. J. Mol. Sci. 2020, 21, 7778. [CrossRef]

94. Sekhon, R.S.; Saski, C.; Kumar, R.; Flinn, B.S.; Luo, F.; Beissinger, T.M.; Ackerman, A.J.; Breitzman, M.W.; Bridges, W.C.; de Leon, N.; et al. Integrated genome-scale analysis identifies novel genes and networks underlying senescence in maize. Plant Cell 2019, 31, 1968-1989. [CrossRef] [PubMed]

95. Zhang, S.; Haider, I.; Kohlen, W.; Jiang, L.; Bouwmeester, H.; Meijer, A.H.; Schluepmann, H.; Liu, C.M.; Ouwerkerk, P.B.F. Function of the HD-Zip I gene Oshox22 in ABA-mediated drought and salt tolerances in rice. Plant Mol. Biol. 2012, 80, 571-585. [CrossRef]

96. Agalou, A.; Purwantomo, S.; Övernäs, E.; Johannesson, H.; Zhu, X.; Estiati, A.; De Kam, R.J.; Engström, P.; Slamet-Loedin, I.H.; Zhu, Z.; et al. A genome-wide survey of HD-Zip genes in rice and analysis of drought-responsive family members. Plant Mol. Biol. 2008, 66, 87-103. [CrossRef] [PubMed]

97. Zhang, T.; Zhao, X.; Wang, W.; Pan, Y.; Huang, L.; Liu, X.; Zong, Y.; Zhu, L.; Yang, D.; Fu, B. Comparative transcriptome profiling of chilling stress responsiveness in two contrasting rice genotypes. PLoS ONE 2012, 7, e0043274. [CrossRef]

98. Baldoni, E.; Mattana, M.; Locatelli, F.; Consonni, R.; Cagliani, L.R.; Picchi, V.; Abbruscato, P.; Genga, A. Analysis of transcript and metabolite levels in Italian rice (Oryzasativa L.) cultivars subjected to osmotic stress or benzothiadiazole treatment. Plant Physiol. Biochem. 2013, 70, 492-503. [CrossRef]

99. Andrews, S. Babraham Bioinformatics-FastQC A Quality Control Tool for High Throughput Sequence Data. Available online: http:/ / www.bioinformatics.babraham.ac.uk/projects/fastqc/ (accessed on 30 September 2021).

100. Bolger, A.M.; Lohse, M.; Usadel, B. Trimmomatic: A flexible trimmer for Illumina sequence data. Bioinformatics 2014, 30, 2114-2120. [CrossRef]

101. Kim, D.; Paggi, J.M.; Park, C.; Bennett, C.; Salzberg, S.L. Graph-based genome alignment and genotyping with HISAT2 and HISAT-genotype. Nat. Biotechnol. 2019, 37, 907-915. [CrossRef] [PubMed]

102. Vogel, J.P.; Garvin, D.F.; Mockler, T.C.; Schmutz, J.; Rokhsar, D.; Bevan, M.W.; Barry, K.; Lucas, S.; Harmon-Smith, M.; Lail, K.; et al. Genome sequencing and analysis of the model grass Brachypodium distachyon. Nature 2010, 463, 763-768. [CrossRef]

103. Mayer, K.F.X.; Waugh, R.; Langridge, P.; Close, T.J.; Wise, R.P.; Graner, A.; Matsumoto, T.; Sato, K.; Schulman, A.; Ariyadasa, R.; et al. A physical, genetic and functional sequence assembly of the barley genome. Nature 2012, 491, 711-716. [CrossRef]

104. Schnable, P.S.; Ware, D.; Fulton, R.S.; Stein, J.C.; Wei, F.; Pasternak, S.; Liang, C.; Zhang, J.; Fulton, L.; Graves, T.A.; et al. The B73 maize genome: Complexity, diversity, and dynamics. Science 2009, 326, 1112-1115. [CrossRef]

105. Matsumoto, T.; Wu, J.; Kanamori, H.; Katayose, Y.; Fujisawa, M.; Namiki, N.; Mizuno, H.; Yamamoto, K.; Antonio, B.A.; Baba, T.; et al. The map-based sequence of the rice genome. Nature 2005, 436, 793-800. [CrossRef]

106. Liao, Y.; Smyth, G.K.; Shi, W. featureCounts: An efficient general purpose program for assigning sequence reads to genomic features. Bioinformatics 2014, 30, 923-930. [CrossRef]

107. Robinson, M.D.; McCarthy, D.J.; Smyth, G.K. edgeR: A Bioconductor package for differential expression analysis of digital gene expression data. Bioinformatics 2010, 26, 139-140. [CrossRef] [PubMed]

108. Jin, J.; Zhang, H.; Kong, L.; Gao, G.; Luo, J. PlantTFDB 3.0: A portal for the functional and evolutionary study of plant transcription factors. Nucleic Acids Res. 2014, 42, D1182-D1187. [CrossRef] [PubMed] 
109. Kinsella, R.J.; Ka, A.; Spudich, G.; Almeida-king, J.; Staines, D.; Derwent, P.; Kerhornou, A.; Kersey, P.; Flicek, P. Ensembl BioMarts: A hub for data retrieval across taxonomic space. Database 2011, 2011, bar030. [CrossRef] [PubMed]

110. Szklarczyk, D.; Gable, A.L.; Lyon, D.; Junge, A.; Wyder, S.; Huerta-Cepas, J.; Simonovic, M.; Doncheva, N.T.; Morris, J.H.; Bork, P.; et al. STRING v11: Protein-protein association networks with increased coverage, supporting functional discovery in genome-wide experimental datasets. Nucleic Acids Res. 2019, 47, D607-D613. [CrossRef] [PubMed]

111. Morgan, M.; Obenchain, V.; Hester, J.; Pagès, H. Summarized Experiment: Summarized Experiment Container. R Package Version 1.24.0. 2021. Available online: https:// bioconductor.org/packages/SummarizedExperiment (accessed on 30 September 2021).

112. Wei, T.; Simko, V. R Package "Corrplot": Visualization of a Correlation Matrix (Version 0.84). 2017. Available online: https: //github.com/taiyun/corrplot (accessed on 30 September 2021).

113. Nguyen, N.T.T.; Contreras-Moreira, B.; Castro-Mondragon, J.A.; Santana-Garcia, W.; Ossio, R.; Robles-Espinoza, C.D.; Bahin, M.; Collombet, S.; Vincens, P.; Thieffry, D.; et al. RSAT 2018: Regulatory sequence analysis tools 20th anniversary. Nucleic Acids Res. 2018, 46, W209-W214. [CrossRef] [PubMed]

114. Higo, K.; Ugawa, Y.; Iwamoto, M.; Korenaga, T. Plant cis-acting regulatory DNA elements (PLACE) database: 1999. Nucleic Acids Res. 1999, 27, 297-300. [CrossRef] [PubMed]

115. Lindemose, S.; Jensen, M.K.; De Velde, J.; O'Shea, C.; Heyndrickx, K.S.; Workman, C.T.; Vandepoele, K.; Skriver, K.; De Masi, F. A DNA-binding-site landscape and regulatory network analysis for NAC transcription factors in Arabidopsis thaliana. Nucleic Acids Res. 2014, 42, 7681-7693. [CrossRef] [PubMed] 